Revista lus et Praxis, Año 21, № 2, 2015, pp. 373 - 414

ISSN 0717 - 2877

Universidad de Talca - Facultad de Ciencias Jurídicas y Sociales

La delimitación marítima en el contexto de la desaparición del territorio estatal como

consecuencia del cambio climático: análisis de los problemas jurídicos

procedimentales y sustanciales de un escenario ya no tan hipotético

Giovanny Andrés Vega - Angela Schembri Peña - Juan Camilo Piñerez

Trabajo recibido el 27 de febrero y aprobado el 20 de mayo de 2015

\title{
La delimitación marítima en el contexto de la desaparición del territorio estatal como consecuencia del cambio climático: análisis de los problemas jurídicos procedimentales y sustanciales de un escenario ya no tan hipotético
}

\author{
Maritime DELIMITATION IN THE CONTEXT OF THE DISAPPEARANCE OF STATE \\ TERRITORY DUE TO CLIMATE CHANGE: ANALYSIS OF PROCEDURAL AND \\ SUBSTANTIAL LEGAL ISSUES OF A NOT THAT HYPOTHETICAL SCENARIO
}

\author{
Giovanny Andrés Vega* \\ Angela SChembri Peña** \\ Juan Camilo Piñerez***
}

\section{RESUMEN}

El presente escrito tiene como propósito aproximarse de manera teórica y descriptiva a los problemas jurídicos sustanciales y procedimentales planteados por un eventual litigio de delimitación marítima ante la Corte Internacional de Justicia, en el supuesto en que el territorio de uno de los Estados desaparecería con posterioridad a la emisión del fallo. El presente escrito complementa la literatura actualmente existente en relación con la potencial desaparición de los Estados-Isla como consecuencia del cambio climático y el incremento del nivel del mar, y sobre la capacidad del derecho internacional para proveer una respuesta satisfactoria. Sin perjuicio de la elucidación descriptiva del derecho internacional relevante a cada uno de los problemas jurídicos

* Giovanny Vega Barbosa, Profesor de Derecho Internacional y Codirector del Grupo de Investigación sobre el Derecho del Mar de la Universidad del Rosario. Bogotá D.C, Colombia. Entrenador del concurso Philip C. Jessup International Moot Court Competition de la misma Universidad. En su vida profesional se ha desempeñado como Asesor del Grupo de Tratados de la Dirección de Asuntos Jurídicos Internacionales del Ministerio de Relaciones Exteriores de la República de Colombia; Coordinador del Grupo Consultivo de la misma Dirección y como Asesor del Grupo Interno de Trabajo de Asuntos ante la Corte Internacional de Justicia de ese Ministerio. Admitido al curso "Directed Studies" en el Curso de Derecho Internacional Público de la Academia de Derecho Internacional de La Haya en verano del año 2013-Director General: James Crawford/Tutora "Directed Studies": Patricia Galvao Tellez. Correo electrónico: giovanny.vega@urosario.edu.co.

** Angela Schembri Peña, abogada de la Universidad del Rosario. Bogotá D.C, Colombia. Integrante del Grupo de Investigación sobre el Derecho del Mar de la misma Universidad. Actualmente, estudiante en la Universidad Paris I Panthéon-Sorbonne, Master I de Derecho Internacional General. Paris, Francia. Correo electrónico: schembri.angela@urosario.edu.co.

*** Juan Camilo Piñerez, abogado de la Universidad del Rosario (Bogotá D.C, Colombia) e integrante del Grupo de Investigación sobre el Derecho del mar de la misma universidad. Orador en representación de la Universidad del Rosario en el concurso Philip C. Jessup International Moot Court Competition (2011) y Coentrenador (2013-2014). Correo electrónico: pinerez.juan@urosario.edu.co. 
referidos, los autores promueven la delimitación marítima como herramienta que puede y debe complementar las actuales estrategias de los Estados-Isla frente a la conservación de sus recursos naturales e independencia, no obstante la desaparición de su territorio como consecuencia de la inhabitabilidad o el sumergimiento.

ABSTRACT

This article purports to analyze descriptively and theoretically the substantial and procedural legal issues derived from a potential litigation on maritime delimitation before the International Court of Justice in a scenario where the territory of one of the States concerned will inevitably disappear after the rendering of the judgment. This work complements the current literature with respect to the potential disappearance of Island-States due to climate change and sea level rise, and about the suitability of public international to provide a satisfactory answer. Together with a descriptive elucidation of the international law relevant to each of the legal issues addressed, the authors encourage Island-State to avail of maritime delimitation as a tool that may strengthen their current political and legal strategies for the preservation of their natural resources and independence notwithstanding the disappearance of their original territory.

\section{Palabras Clave}

Delimitación marítima, Cambio climático, Corte Internacional de Justicia

\section{KEYWORDS}

Maritime delimitation, Climate change, International Court of Justice

\section{Introducción}

El cambio climático y sus consecuencias antropogénicas son hoy una realidad cuyo reconocimiento por parte de la comunidad internacional encuentra expresión en el numeral $2^{\circ}$ del artículo 1 de la Convención Marco de las Naciones Unidas sobre Cambio Climático ("UNFCCC" por sus siglas en inglés) ${ }^{1}$. Así mismo, el Panel Intergubernamental sobre el Cambio Climático ha reconocido que dentro de los efectos adversos del cambio climático se incluye el incremento del nivel del mar y que este fenómeno afecta especialmente a las islas de poca altitud ${ }^{2}$.

Siendo este un supuesto que podríamos Ilamar pacífico, la doctrina internacional moderna se ha dado a la tarea de abordar -y en algunos casos anticipar- los problemas jurídicos que en el derecho internacional público podría propiciar la eventual desaparición del territorio estatal como consecuencia del calentamiento global y sus efectos en el incremento del nivel del mar. Así mismo, los tratadistas se han ocupado de cuestiones propias del derecho del mar como el carácter ambulatorio de las líneas de base para la medición de la

\footnotetext{
1 De conformidad con el artículo $1^{\circ}$ de la Convención: "2. Climate change' means a change of climate which is attributed directly or indirectly to human activity that alters the composition of the global atmosphere and which is in addition to natural climate variability observed over comparable time periods". 1771 UNTS 107.
}

2 Moss et al. (1998), p. 339. 
anchura del mar territorial. Como aspecto en común, estos dos escenarios han sido abordados a partir de instituciones clásicas y básicas del derecho internacional público, entre ellas, la noción de territorio y Estado; las doctrinas de la sucesión y de la continuidad; y la noción de isla bajo el derecho internacional consuetudinario.

De otra parte, una problemática de menor atención ha sido la cuestión de la delimitación de los espacios marítimos en eventos en donde al menos uno de los Estados concernidos experimenta el riesgo de desaparición de su territorio. Aún más inexplorado resulta el anterior supuesto en sede de adjudicación internacional. A este respecto corresponde señalar que la cuestión de la inestabilidad de las costas no es un problema ajeno a la jurisprudencia internacional sobre delimitación marítima, especialmente cuando lo que se aborda es la delimitación del mar territorial ${ }^{3}$. Sin embargo, el supuesto en que uno de los Estados parte del proceso de delimitación perdería su territorio con posterioridad a la resolución judicial del conflicto, genera problemas jurídicos que se proyectarían y llevarían al límite la aplicación de principios básicos del derecho del mar-la tierra domina el mar- y de la administración de justicia internacional -imposibilidad de emitir pronunciamientos sin utilidad práctica-. De otra parte, fallos arbitrales recientes como el del Tribunal constituido bajo el Anexo VII de la Convención sobre el Derecho del Mar en el Arbitraje sobre la Frontera Marítima en la Bahía de Bengala entre Bangladesh e India ${ }^{4}$, nos permiten encontrar en la adjudicación internacional una herramienta útil para que los Estados-Islas en riesgo de sumergimiento consoliden sus derechos marítimos frente a sus vecinos.

Los anteriores supuestos constituyen el objeto de estudio del presente escrito no solo por su importancia y novedad temática intrínseca, sino porque en nuestra consideración, las precitadas circunstancias -las que vendrán y las que ya atestiguamos- disponen de la potencialidad para generar controversias jurídicas internacionales de una gran complejidad. También resulta del objeto del presente escrito el análisis de la dimensión litigiosa de estos supuestos. En nuestra consideración, esta dimensión es de atención obligada máxime cuando se observa que los tribunales internacionales en general y la Corte Internacional de Justicia en particular, constituyen hoy en día un foro eficaz y confiable para la resolución de las disputas marítimas más importantes ${ }^{5}$.

\footnotetext{
3 Territorial and Maritime Dispute between Nicaragua and Honduras in the Caribbean (2007), p. 659.

${ }^{4}$ Award in the matter of the Bay of Bengal Maritime Boundary Arbitration between The People's Republic of Bangladesh and the Republic of India (2014).

${ }^{5}$ Case concerning the Maritime Dispute (Peru v. Chile), Application instituting proceedings, 16 January 2008. Disponible en: http://www.icj-cij.org/docket/files/137/14385.pdf. [visitado el 28/06/2014]. El caso de los Estados latinoamericanos es ilustrativo a este respecto. En efecto, aunque los Estados de las
} 
Introducir al lector a los precitados problemas jurídicos en el marco de un proceso de delimitación es consecuencia de la convicción de los autores en una premisa básica: que la adjudicación internacional constituye una herramienta útil pero inexplorada en los propósitos de los Estados-Isla amenazados por el incremento en el nivel del mar. En nuestro entendimiento, y así lo defendemos, el fallo de un tribunal internacional competente dispone del valor jurídico suficiente para cristalizar las fronteras marítimas de los Estados-Isla con sus vecinos inmediatos de manera previa al total sumergimiento de la base territorial del Estado. Esta herramienta puede y debe sumarse a las políticas y esfuerzos actuales de los Estados-Isla para asegurar la soberanía sobre sus recursos naturales, sus territorios originales y en general, su independencia. El valor agregado del recurso al litigio internacional reside en que este último da lugar a un instrumento de carácter final y jurídicamente vinculante para los Estados concernidos en el proceso de delimitación. No obstante, entendiendo que la vía judicial involucra problemas jurídicos procedimentales y sustanciales altamente complejos, nuestro escrito los advierte y provee los elementos conceptuales necesarios para su comprensión y desarrollo.

Sin perjuicio de las consideraciones introductorias precedentes, y aunque no constituyen el objeto del presente estudio, nuestra investigación nos permitió constatar la existencia de una importante producción académica en relación con otros problemas jurídicos asociados al cambio climático y periféricamente al sumergimiento del territorio estatal. Entre estos se cuentan destacados esfuerzos doctrinales por defender la existencia jurídica de la categoría de refugiado medioambiental o "environmental refugee" , como medida dirigida a abordar, desde el derecho internacional de los derechos humanos, el supuesto de aquella persona o grupo poblacional que sale de su Estado ante la amenaza inminente de que sus derechos sean afectados de forma grave y masiva por la erosión del territorio o, por su inundación y posterior inhabitabilidad .

Américas permanecieron distantes en algún período (1950-1983), su confianza histórica en la Corte Internacional de Justicia se ve evidenciada en el sometimiento de las más importantes controversias ante la Corte, entre ellas sobresalen las relativas a la delimitación marítima de sus espacios convergentes. Fuentes (2014), pp. 79-81. Ana Elizabeth Villalta, miembro del Comité Jurídico Interamericano, resalta el establecimiento de la Corte Centro-Americana de Justicia, no solo por ser el primer tribunal internacional moderno -creado mediante el Acuerdo de Washington de 1920 y en funcionamiento incluso antes que la Corte Permanente de Justicia Internacional- pero sobre todo por su creación para servir a los más importantes propósitos de los pueblos de la región. Villalta (2006), p. 65.

${ }^{6}$ Duong et al. (2009-2010), p. 607.

7 Aunque un desarrollo exhaustivo del asunto escapa a los propósitos del presente escrito, consideramos relevante señalar que en opinión de un importante sector de la doctrina, más allá de reducidas instancias de práctica estatal como la "Declaración de Cartagena" y las declaraciones públicas de altos funcionarios de Estados-Islas actualmente en riesgo de desaparición, no es posible verificar el elemento 
Así mismo, es posible evidenciar una abundante literatura en relación con la validez jurídica de reclamaciones de compensación por parte de EstadosIslas contra Estados que históricamente han generado los más altos niveles de producción de gases de efecto invernadero. Las discusiones a este respecto versan sobre los dos elementos de la responsabilidad internacional por el hecho internacionalmente ilícito, i.e., (1) atribución de la conducta al Estado y (2) la violación de una obligación jurídicamente vinculante ${ }^{8}$. De una parte, la doctrina que apoya las reclamaciones de compensación parece encontrar en la denominada no harm-rule ${ }^{9}$, la fuente legal que permite responsabilizar al Estado por no ejercer la debida diligencia para prevenir, controlar o reducir los efectos medioambientales nocivos que las actividades industriales en su territorio o bajo su jurisdicción generan en terceros Estados ${ }^{10}$. El sector doctrinario contrario señala que en este supuesto no es posible evidenciar ninguno de los elementos que componen la responsabilidad internacional del Estado por el hecho internacionalmente ilícito. En primer lugar, se alega que la contribución general al problema del calentamiento global genera un criterio de atribución demasiado amplio, débil, indirecto y sin soporte legal alguno el cual, de aceptarse, repercutiría en que todos los Estados del mundo estuviesen obligados a compensar en función de su emisión histórica de gases de efecto invernadero ${ }^{11}$. En relación con la norma sustancial infringida, esta vertiente doctrinal señala que los grandes emisores de gases de efecto invernadero no pueden ser responsabilizados por conductas que solo en fecha reciente han encontrado el suficiente consenso para ser restringidas o limitadas, y cuya prohibición solo es verificable en algunos instrumentos convencionales ${ }^{12}$.

objetivo ni la opinio juris necesaria para señalar que la categoría de "refugiado medioambiental" hace parte del derecho internacional consuetudinario.

${ }^{8}$ ILC Draft Articles on State Responsibility of States for the Internationally Wrongful Acts with Commentaries, pp. 34 y ss.

9 Pulp Mills on the River Uruguay (2010), p. 14, para. 193; Legality of the Threat or Use of Nuclear Weapons (1996), p. 226, para. 29; Construction of a Road in Costa Rica Along the San Juan River (Nicaragua v. Costa Rica), Order, I.C.J, 13 December 2013, para. 9; Rio Declaration on Environment and Development) (1992), pple.2; Declaration of the United Nations on the Human Environment (1972), pple.21; Draft Articles on Prevention of Trans-boundary Harm from Hazardous Activities, with commentaries, Arts. 1, 3.

10 TOl Y VerHeyen (2004), p. 1112.

11 Barton (2001), p. 83; Davis (2005), p. 49; Stallard (2009), pp. 165-176.

${ }^{12}$ El Grupo de Trabajo de la Comisión de Derecho Internacional liderado por el Profesor Martti Koskiniemi aborda la intertemporalidad como una regla de dos partes, a saber, una que se limita al reconocimiento del derecho que es contemporáneo con el hecho que se analiza, y otra que acepta que se tomen en consideración los cambios del derecho en el tiempo. Ver: ILC, Fragmentation of International Law: Difficulties Arising from the Diversification and Expansion of International Law, p. 240, para. 475. Para el efecto se hace referencia al célebre párrafo del Arbitral Max Huber en el caso Isla Palmas: "... a 
Inspirado en las anteriores consideraciones y con el propósito de abordar las temáticas y propósitos aludidos, el presente trabajo contiene 4 partes principales:

La primera parte describe un supuesto fáctico en donde los problemas jurídicos a tratar en las dos partes subsiguientes se introducen mediante una situación hipotética (I). El escenario planteado contempla una disputa que involucra problemas jurídicos sobre la existencia del Estado, las reclamaciones marítimas por parte de Estados costeros que día a día pierden la batalla frente al mar, y la cuestión de la delimitación marítima en el evento en donde al menos uno de los Estados concernidos perdería su territorio originario con posterioridad al fallo de delimitación. La disputa planteada encuentra en la Corte Internacional de Justicia (en adelante también la Corte) el foro para su resolución. La escogencia de la Corte no es producto del azar y, por el contrario, tiene como propósito evidenciar, adicionalmente, los problemas procedimentales a los que se vería enfrentado un Estado cuyo territorio desaparecería en un futuro próximo como consecuencia del cambio climático y el correlativo incremento del nivel de las aguas. Paradójicamente, el caso hipotético parte de la premisa del consentimiento de los Estados a la jurisdicción de la Corte Internacional de Justicia, requisito que en la práctica suele frustrar la solución de fondo de las más importantes controversias ${ }^{13}$. La intención no es otra que centrar la discusión en la existencia del Estado como prerrequisito estatutario de la jurisdicción con independencia de una base consensual para esta.

La segunda parte aborda las cuestiones procedimentales que un litigio en los términos y circunstancias descritas podría suscitar. En atención a que el litigio ante la Corte Internacional de Justicia está reservado para Estados parte del Estatuto, esta sección está dirigida a ilustrar sobre los elementos conceptuales

juridical fact must be appreciated in the light of the law contemporary with it, and not the law in force at the time when a dispute arises" ... "The same principle which subjects the act creative of a right to the law in force at the time the right arises, demands that the existence of the right, in other words, its continued manifestations, shall follow the conditions required by the evolution of law". Ver Island of Palmas case (1928), pp. 845 y 839.

13 Un ejemplo histórico lo constituye la imposibilidad de la República Democrática del Congo de lograr un fallo de fondo sobre la responsabilidad de Ruanda por hechos que en su consideración eran constitutivos de genocidio y tortura, entre otros. Armed Activities on the Territory of the Congo (New Application: 2002 (2006), p. 6. Más recientemente, Islas Marshall presentó varias solicitudes contra potencias nucleares que, en su consideración, han incumplido con sus obligaciones bajo el Tratado sobre No Proliferación de Armas Nucleares. Sin embargo, en relación con varios de ellos, Islas Marshall apela al forum prorrogatum y por lo tanto, a un consentimiento posterior inequívoco de la jurisdicción de la Corte, en ausencia de un consentimiento expreso previo. A la fecha, la Lista General de casos de la Corte solo contiene los casos contra Estados que han manifestado su consentimiento de conformidad con el numeral $2^{\circ}$ del artículo 36 de su Estatuto. Al respecto ver aplicaciones contra India, Reino Unido y Pakistán. Case concerning Negotiations relating to Cessation of the Nuclear Arms Race and to Nuclear Disarmament (Marshall Islands v. Pakistan), Application Instituting Proceedings against Pakistan/United Kingdom/India, submitted on 24 april 2014. 
que gobernarían una determinación sobre la supervivencia del Estado pese a la pérdida de su territorio originario, así como a evidenciar la relevancia de esta determinación bajo los artículos 34 y 35 del Estatuto de la Corte. El análisis se efectuará a la luz de la noción de "prerrequisito" de jurisdicción de la Corte Internacional de Justicia, discusión obligada en todo litigio ante la Corte y pertinente en el escenario sub examine, pero que en general ha pasado desapercibida en la doctrina escrita al respecto hasta la fecha. En este estadio, los autores defenderán que, por razones de buena administración de justicia, una determinación sobre la continua existencia del Estado no debería ser objeto de pronunciamiento, salvo en el evento en que uno de los Estados genere un cuestionamiento en los términos del artículo 34.

La tercera parte analiza la viabilidad de la delimitación marítima en eventos en donde la evidencia científica acredita que al menos uno de los Estados perdería su territorio originario con posterioridad a la emisión del fallo de delimitación (III). Esta parte se compone de dos secciones: la primera de ellas dirigida a analizar si un Estado-Isla perdería sus derechos marítimos como consecuencia del sumergimiento y la inhabitabilidad de parte o la totalidad de su territorio (1); la segunda, se encamina a determinar si, en un escenario en donde el Estado-Isla aún preserva el derecho a generar proyecciones marítimas, la delimitación sería inviable como consecuencia de la desaparición eventual del territorio en el que se ubican los puntos de base. En esta última sección se efectuará un análisis exhaustivo del pronunciamiento de 7 de junio de 2014 del Tribunal Arbitral constituido bajo el Anexo VII de la Convención de Naciones Unidas sobre el Derecho del Mar y que decidió en el Arbitraje sobre la Frontera Marítima en la Bahía de Bengala entre Bangladesh e India ${ }^{14}$.

La cuarta parte, aunque conclusiva, contiene adicionalmente las propuestas de los autores en relación con la forma en que el litigio ante la Corte Internacional de Justicia, y ante instancias de adjudicación judicial internacional en general, puede ser utilizado por los Estados afectados por el cambio climático para garantizar la intangibilidad de sus derechos marítimos (IV).

Sin perjuicio de su composición, es pertinente indicar que el presente trabajo acomete un análisis teórico, casuístico y propositivo de 3 supuestos de litigio internacional intrínsecamente relacionados y que son consecuencia de los efectos del cambio climático en el territorio. La decisión de introducir los problemas jurídicos a tratar mediante un caso hipotético tiene como propósito propiciar que el lector aborde el estudio de los diferentes problemas jurídicos ya

\footnotetext{
14 Award in the matter of the Bay of Bengal Maritime Boundary Arbitration between The People's Republic of Bangladesh and the Republic of India (2014).
} 
no de forma abstracta, sino con ocasión de la situación planteada ${ }^{15}$, la cual se inspira en las realidades actuales de Estados-Islas de baja altitud como Tuvalu, Kiribati e Islas Marshall. Finalmente, corresponde precisar que no obstante la existencia de referencias incidentales a la situación hipotética, el propósito de los autores no es el de proveer una respuesta concreta. De esta forma, la aproximación es ante todo descriptiva con miras a dotar al lector de las herramientas necesarias para aproximarse de manera crítica e independiente a los problemas jurídicos planteados.

\section{Situación hipotética}

La República de Andrea es un Estado-Isla cuyos derechos marítimos se solapan con los de los Estados Unidos de Niamuro, la República de Aurina, la Federación de Mabuba y la República Independiente de Saratobo. La economía esencialmente industrial de estos últimos Estados los ubica en el grupo de más grandes generadores de gases de efecto invernadero.

Como consecuencia de su trabajo conjunto y mancomunado durante la Tercera Conferencia sobre el Derecho del Mar, los 5 Estados presentaron una declaración conjunta mediante la cual reconocieron la jurisdicción obligatoria de la Corte Internacional de Justicia en relación con todos los asuntos que, estando gobernados por el derecho internacional del mar, pudieran ser objeto de disputa entre las Partes. La declaración es ampliamente analizada en libros de texto y se reconoce en el derecho internacional como la "GLOSOC" por sus siglas en inglés "Great Law of the Sea Optional Clause Declaration". Todos los Estados son Miembros de las Naciones Unidas y por lo tanto, ipso facto Partes del Estatuto de la Corte Internacional de Justicia (en adelante también "la Corte").

Estudios científicos, entre ellos, los del Panel Intergubernamental sobre Cambio Climático, anticipan que el territorio de Andrea resultará inhabitable en un período inferior a 10 años. Sin embargo, el 95\% del territorio de la República de Andrea ya se encuentra inundado y el restante se inunda en pleamar. Esta situación ha generado que gran parte de la población haya decidido migrar a otros Estados, entre ellos, los Estados industrializados vecinos. Pese a la precariedad de la situación, la implementación de proyectos de innovación ha permitido que la vida en Andrea se desenvuelva sobre plataformas metálicas que cubren la totalidad de la isla.

15 La experiencia de los "moot court competitions" -y con especial cariño hacemos referencia al Philip C. Jessup- nos demuestra que la aproximación a problemas jurídicos complejos a partir del análisis de un caso hipotético no solo es útil desde un punto de vista pedagógico, sino que se constituye en un verdadero semillero para la formación de los próximos practicantes y académicos del derecho internacional público. Por lo tanto, este artículo es también un homenaje a aquellos estudiantes que con valentía asumen tan importante reto en las diferentes facultades de derecho de Latinoamérica y el mundo. 
De otra parte, el Gobierno de Andrea ha empezado a movilizar a la mayoría de sus Ministerios a una isla vecina que compró al Estado Democrático de Horcano, ubicado a 300 millas de la República de Andrea. Los términos del acuerdo con el Estado de Horcano demuestran que la República de Andrea solo dispondrá de prerrogativas de usufructuario, conservándose en el Estado territorial las funciones en materia de defensa, migratoria, fiscal y sanitaria. Sin embargo, se reconoce que durante la vigencia del Acuerdo no aplicarán en ese territorio las leyes ni la jurisdicción del Estado de Horcano, sino únicamente las de la República de Andrea.

La comunidad internacional ha manifestado gran preocupación por el destino de la República de Andrea. Como efecto colateral, muchos Estados han decidido suspender las negociaciones de tratados bilaterales con esta República ante la incertidumbre sobre el cumplimiento de sus obligaciones. Mediante la Resolución 1803 de 2013, aprobada por consenso en la Asamblea General de las Naciones Unidas, los Estados Miembros reconocieron el derecho inherente de la República de Andrea a continuar existiendo y adicionalmente invitaron a la aplicación permanente del principio pacta sunt servanda en relación con las obligaciones ya contraídas.

El 1 de enero de 2013, la República de Andrea presentó una Solicitud ante la Corte Internacional de Justica ${ }^{16}$, mediante la cual requirió el trazado de una línea única de delimitación que fije la frontera marítima en relación con las áreas de superposición de su mar territorial, zona económica exclusiva y la plataforma continental con los Estados Unidos de Niamuro, la República de Aurina, la Federación de Mabuba y la República Independiente de Saratobo, en lo que fuere procedente. Como segunda pretensión, la República de Andrea solicita se declare la obligación de compensarla por los perjuicios económicos derivados de la inminente desaparición de su territorio, así como por los gastos en los que ha incurrido en la compra de una isla y en el traslado de su aparato gubernamental y población a esta. El demandante solicita sin embargo que la cuestión sobre la compensación y su monto sean abordados en un procedimiento posterior que dependerá de la decisión en los méritos de sus pretensiones ${ }^{17}$. La República de Andrea fundamenta la jurisdicción de la Corte en el numeral $2^{\circ}$ del artículo 36 de la Corte Internacional de Justicia y para el efecto invoca el contenido de la GLOSOC.

Los Estados demandados fueron notificados por el Secretario de la Corte de conformidad con el procedimiento previsto en el numeral $2^{\circ}$ del artículo 40

${ }^{16}$ Estatuto de la Corte Internacional de Justicia, artículo 40 (1).

17 Aunque sirve a los propósitos de delimitación temática del presente escrito, esta práctica no es extraña en el procedimiento ante la Corte. Al respecto ver: Corfu Channel (1949), p. 244; Ahmadou Sadio Diallo (2012), p. 324. 
del Estatuto. Después de superar su gran sorpresa por lo que consideraron una actuación "sorpresiva", "mezquina", "ilegal" y "torpe" por parte de la República de Andrea, y dentro del término previsto por la Corte para que esta presentara su escrito de Memoria, los Estados demandados presentaron 4 escritos idénticos de excepciones preliminares mediante los cuales solicitaron lo siguiente:

Primero, que la Corte declare que no tiene jurisdicción porque con independencia de la constatación de una base de jurisdicción conforme al artículo 36 del Estatuto, la República de Andrea no cumple con los requisitos previstos por el artículo 34 del Estatuto para comparecer ante la Corte;

Segundo, que la Corte declare que no dispone de jurisdicción para resolver la materia objeto de la disputa porque ante la inminente desaparición del territorio de la República de Andrea, pronunciarse de fondo implicaría un desconocimiento de los límites impuestos por su función judicial;

Tercero, como solicitud subsidiaria, y solo en el evento en que la Corte asuma jurisdicción en el presente caso, que la Corte declare infundadas las pretensiones de la República de Andrea porque, en la fecha de la Solicitud Andrea ya no posee territorio $y$, por lo tanto, no existe un evento de superposición de derechos marítimos en el presente caso;

Cuarto, como solicitud subsidiaria, y solo en el evento en que la Corte asuma jurisdicción en el presente caso, que declare: Que ante la inestabilidad del territorio del demandante, no es posible proceder a la delimitación (a); Que bajo el derecho internacional vigente, los Estados demandados no son responsables por un hecho internacionalmente ilícito y por lo tanto, no se encuentran legalmente obligados a compensar a la República de Andrea por los daños supuestamente sufridos como consecuencia de los efectos del calentamiento global (b). Sin embargo, los Estados solicitan que este último alegato solo se estudie en el evento excepcional en el que la Corte falle a favor del demandante.

\section{Las cuestiones procedimentales}

De conformidad con el numeral $2^{\circ}$ del artículo 36 del Estatuto de la Corte Internacional de Justicia, los Estados de nuestra situación hipotética reconocieron la jurisdicción de la Corte "sin restricción alguna y en relación con todos los asuntos que, estando gobernados por el derecho internacional del mar, fueran objeto de disputa entre las Partes". No obstante, según lo representa la plataforma fáctica expuesta, en el momento de presentar su Solicitud ante la Corte Internacional de Justicia, el 95\% del territorio de la República de Andrea se encontraba inundado y el restante se inundaba en pleamar. Adicionalmente, la evidencia científica ya anticipaba que en 10 años el territorio resultaría inhabitable. Así mismo, gran parte de la población había emigrado a Estados vecinos y el aparato gubernamental había sido reubicado. Ante este escenario, 
los Estados demandandos reclaman que la Corte declare su falta de jurisdicción por ausencia de uno de los prerrequisitos de la jurisdicción de la Corte.

A la luz de estas consideraciones y de los hechos preestablecidos, a continuación se aborda el estudio de la primera excepción preliminar propuesta, y del derecho aplicable a su resolución. No obstante, con un propósito eminentemente pedagógico, se introduce al lector de manera previa a la noción de prerrequisito de jurisdicción en general.

\subsection{Sobre los prerrequisitos de jurisdicción en general}

Bajo la teoría general de la adjudicación internacional, la jurisdicción de los tribunales depende necesariamente del consentimiento del Estado ${ }^{18}$. Como consecuencia, un Estado que no ha manifestado, expresa o inequívocamente su consentimiento, no puede ser constreñido a resolver sus controversias jurídicas con otro Estado ante un tribunal internacional. En el marco de la Corte Internacional de Justicia, la necesidad del consentimiento se expresa en el artículo 36 de su Estatuto, el cual contiene cuatro fuentes de jurisdicción, a saber: i) la declaración de reconocimiento de la jurisdicción obligatoria de la Corte ("optional clause") ${ }^{19}$; ii) el Acuerdo Especial o compromiso 20 ; iii) la cláusula compromisoria ${ }^{21}$; iv) el forum prorogatum.

No obstante, la Corte Internacional de Justicia ha señalado con claridad que existen condiciones de su jurisdicción que no dependen del consentimiento estatal y que por lo tanto, deberán ser establecidas por la Corte ex ante, ex oficio y con independencia del consentimiento estatal bajo los términos del artículo 36. A estas condiciones necesarias de la jurisdicción de la Corte le llamamos prerrequisitos, por cuanto su análisis antecede el análisis del consentimiento a la jurisdicción de la Corte.

\footnotetext{
18 Shany (2014), p. 70. Stanimir (2006), pp. 29-38.

19 Para efectos de comprender el alcance de las expresiones "ipso facto", "reciprocidad" y "sin necesidad de acuerdo especial" se recomienda ver Case concerning right of passage over Indian territory (1957), p. 125.

20 Proporcionalmente son pocos los casos que se han tramitado ante la Corte Internacional de Justicia de conformidad con un Acuerdo Especial o compromis. Entre ellos el Acuerdo Especial de 21 de julio de 1970 entre Burkina Faso y Niger por el que se sometió ante la Corte la "Frontier Dispute ( (2005), p. 90; El acuerdo especial de 31 de agosto de 1990 entre Libia y Chad en el caso de la Territorial Dispute (1994), p. 6.

${ }^{21}$ La disputa entre Alemania e Italia en relación con el caso de las inmunidades jurisdiccionales se resolvería en virtud de la cláusula compromisoria contenida en el artículo 1 de la Convención Europea para el Arreglo Pacífico de Disputas del 29 de abril de 1957. Ver: Jurisdictional Immunities of the State (2012), p. 99. Más recientemente, Application of the International Convention on the Elimination of All Forms of Racial Discrimination (2011), p. 70.
} 
En su célebre decisión en el caso Northern Cameroons, la Corte Internacional de Justicia se refirió a la naturaleza judicial de su función como un verdadero límite que, como Corte de Justicia, no puede ignorar y que condiciona su funcionamiento con independencia de la existencia de una base consensual de jurisdicción conforme al artículo 36 del Estatuto. El párrafo nuclear del histórico pronunciamiento expresa lo siguiente:

"There are inherent limitations on the exercise of the judicial function which the Court, as a court of justice, can never ignore. There may thus be an incompatibility between the desires of an applicant, or, indeed, of both parties to a case, on the one hand, and on the other hand the duty of the Court to maintain its judicial character. The Court itself, and not the parties, must be the guardian of the Court's judicial integrity".$^{22}$

La función judicial emerge entonces como un verdadero prerrequisito pues, con independencia del consentimiento de los Estados a su jurisdicción, la Corte debe constatar que la materia sub examine no afecta su naturaleza de Corte de Justicia para la resolución de controversias jurídicas entre Estados. En la decisión precitada, la Corte se refirió en específico a supuestos que contrariaban su carácter judicial, entre ellos, el pronunciamiento sobre las relaciones económicas entre las partes ${ }^{23}$ y la forma de implementar uno de sus pronunciamientos ${ }^{24}$. Sin embargo, estos supuestos disponen de un carácter estrictamente enunciativo y, por lo tanto, en relación con cada asunto sometido ante ella, la Corte debe verificar que el asunto es susceptible de ser resuelto en ejercicio de su función como una corte judicial para la administración de justicia ${ }^{25}$.

Por su misma naturaleza, el prerrequisito de mayor mención y desarrollo en la jurisprudencia de la Corte es el de la existencia de una disputa entre las partes, y básicamente exige que entre ellas sea posible constatar objetivamente una controversia sobre una cuestión de hecho o de derecho ${ }^{26}$. Otro prerrequisito de importante y extenso tratamiento en la jurisprudencia de la Corte es la prohibición contenida en el artículo 59 del Estatuto, y que le impide a

22 Case concerning the Northern Cameroons (1963), p. 15, p. 29.

23 Free Zones of Upper Savoy and the District of Gex (1932), p. 161.

${ }^{24}$ Haya de la Torre Case (1951), pp. 78-79

25 Northern Cameroons (1963), p. 15, p. 30.

${ }^{26}$ Interpretation of Peace Treaties with Bulgaria, Hungary and Romania, First Phase (1950), p. 74; South West Africa (1962), p. 328; New Application: 2002) (Democratic Republic of the Congo v. Rwanda) (2006), p. 40, para. 90); Application of the International Convention on the Elimination of All Forms of Racial Discrimination (2011), p. 84, para. 30. 
esta pronunciarse sobre un proceso en donde los derechos de terceros Estados constituirían el objeto material mismo de la disputa ante la Corte ${ }^{27}$.

Por el contrario, la naturaleza misma de los prerrequisitos consagrados en los artículos 34 y 35 del Estatuto han generado que su tratamiento haya sido más bien escaso en la jurisprudencia de la Corte. En todo caso, como se observa en el subtítulo siguiente, las contadas decisiones sobre el particular contienen importantes pronunciamientos y reglas jurídicas que contribuyen a generar claridad sobre el rol del consentimiento estatal en relación con los requisitos estatutarios para el ejercicio de la jurisdicción y sobre la necesidad sine qua non de corroborar la calidad o status de quienes comparecen ante la Corte.

\subsection{La existencia del Estado como un prerrequisito de la jurisdicción de la Corte}

Los numerales $1^{\circ}$ de los artículos 34 y 35 del Estatuto de la Corte expresan lo siguiente, respectivamente:

"1. Sólo los Estados podrán ser partes en casos ante la Corte".

"1. La Corte estará abierta a los Estados parte en este Estatuto"28.

Las precitadas disposiciones consagran al mismo tiempo requisitos de comparecencia ante la Corte -que quien comparezca disponga del estatus jurídico de Estado y que ese Estado sea parte del Estatuto-, y un limitante del ejercicio de la jurisdicción de la Corte -solo resolver disputas entre Estados-. Según se anticipó, ambas disposiciones consagran prerrequisitos estatutarios de la jurisdicción de la Corte ${ }^{29}$.

El supuesto previsto en el artículo 34 del Estatuto no ha sido objeto de un pronunciamiento directo por parte de la Corte Internacional de Justicia. Sin embargo, en su Fallo de excepciones preliminares en el caso sobre la Aplicación de la Convención del Genocidio, la Corte debió abordar un argumento formulado por [la otrora] Yugoslavia, Estado que alegaba que, siendo

\footnotetext{
27 De conformidad con el artículo 59 del Estatuto: "La decisión de la Corte no es obligatoria sino para las partes en litigio y respecto del caso que ha sido decidido". La evolución de la posición de la Corte en relación con el denominado "tercer Estado necesario" puede rastrearse en los siguientes casos: Case of the Monetary Gold Removed from Rome in 1943 (1954), p. 19; Certain Phosphate Lands in Nauru (1992), p. 240. Recientemente, aunque sin un rol protagónico dentro del razonamientode la Corte: Application of the Interim Accord of 13 September 1995 (2011), p. 644.

${ }^{28}$ Estatuto de la Corte Internacional de Justicia.

${ }^{29}$ En todo caso, el análisis del numeral $1^{\circ}$ del artículo 35 del Estatuto debe ser complementado con una referencia necesaria al numeral $1^{\circ}$ del artículo 93 de Carta de las Naciones Unidas, de la cual el Estatuto es parte integrante, que indica que los Miembros de las Naciones Unidas son ipso facto partes en el Estatuto de la Corte. 1 UNTS XVI.
} 
la base de jurisdicción invocada el artículo XI de la Convención sobre la Prevención y Sanción del Crimen de Genocidio, esa disposición no había entrado en vigor entre las partes ya que estas no se reconocían mutuamente como Estados. De esta forma:

"the conditions necessary to found the consensual basis of the Court's jurisdiction were therefore lacking" ${ }^{\prime 30}$.

En reiteración de una regla trascendental dentro del litigio ante la Corte, esta señaló que aunque las condiciones de jurisdicción y admisibilidad deben encontrarse cumplidas en el momento de la presentación de la Solicitud o del acto que da inicio al procedimiento, la Corte no puede penalizar a uno de los litigantes por defectos procedimentales que fácilmente podrían remediarse con posterioridad a la fecha crítica antes mencionada ${ }^{31}$. A continuación, la Corte constató que aunque la Solicitud se había radicado el 20 de marzo de 1993 -fecha en la que los Estados no se reconocían mutuamente-, desde el 14 de diciembre de 1995 -en virtud del artículo X del Acuerdo Dayton-Paris-, los Estados habían aceptado la existencia del otro como soberano dentro de sus respectivas fronteras territoriales. De esta forma, en lo que la doctrina más autorizada ha considerado una aceptación implícita de la teoría declarativa del reconocimiento ${ }^{32}$, la Corte consideró que no resultaba necesario pronunciarse sobre los efectos que la ausencia de ese reconocimiento había tenido en la relación convencional entre los Estados ${ }^{33}$.

Por su parte, el prerrequisito previsto en el artículo 35 fue abordado de forma exhaustiva por la Corte en el caso de la Legalidad del Uso de la Fuerza (Serbia y Montenegro c. Bélgica ${ }^{34}$. No obstante, como se observa a continuación, las reglas jurídicas procedimentales estructuradas por la Corte parecen ser igualmente aplicables al prerrequisito del artículo 34.

Las consideraciones de la Corte en el caso en comento se iniciaron con una precisión: que casos anteriores en donde el demandante había invocado diversas fuentes de jurisdicción -y en donde la Corte había manifestado su libertad para escoger aquella que le permitiera resolver la disputa de forma más directa

30 Application of the Convention on the Prevention and Punishment of the Crime of Genocide (1996), p. 613, para. 25 in fine.

31 Application of the Convention on the Prevention and Punishment of the Crime of Genocide (1996), p. 613, para. 26.

32 CRAWFord considera que con la inclusión del reconocimiento dentro de esos defectos procedimentales de fácil resolución la Corte le restó toda connotación sustancial al acto de reconocimiento. CRAWFORD (2006), p. LVI.

${ }^{33}$ Application of the Convention on the Prevention and Punishment of the Crime of Genocide (1996), p. 613 , para. 26.

${ }^{34}$ Legality of Use of Force (2004), p. 279. 
y conclusiva- ${ }^{35}$, no eran asimilables al caso sub examine. Lo anterior, porque en este caso los Estados demandados habían puesto en duda el derecho del demandante a comparecer ante la Corte ${ }^{36}$. Sobre el particular, la Corte manifestó y reiteró el carácter "fundamental" y previo de la determinación de si un Estado es o no parte del Estatuto en el momento de la presentación de la Solicitud ${ }^{37}$. A continuación, la Corte señaló, en los siguientes términos, que solo Estados, y Estados parte del Estatuto, pueden activar válidamente la jurisdicción de la Corte conforme a una de las fuentes de jurisdicción previstas en el artículo 36, y que su función se encuentra sujeta a la corroboración de esas circunstancias:

"In that situation, subject to any application of paragraph 2 of that Article, Serbia and Montenegro could not have properly seised the Court, whatever title of jurisdiction it might have invoked, for the simple reason that Serbia and Montenegro did not have the right to appear before the Court.

The Court can exercise its judicial function only in respect of those States which have access to it under Article 35 of the Statute. And only those States which have access to the Court can confer jurisdiction upon it.

It is the view of the Court that it is incumbent upon it to examine first of all the question whether the Applicant meets the conditions laid down in Articles 34 and 35 of the Statute and whether the Court is thus open to $i t$. Only if the answer to that question is in the affirmative will the Court have to deal with the issues relating to the conditions laid down in Articles 36 and 37 of the Statute of the Court" ${ }^{\prime \prime 3}$. (Destacado fuera de texto).

Aunque la parte final del párrafo precitado destaca que no existe duda sobre el cumplimiento del requisito previsto en el artículo 34 del Estatuto por parte de Serbia ${ }^{39}$, el pronunciamiento es substancial en relación con este artículo por cuanto la determinación de la Corte se efectúa de manera previa al análisis de cualquier pronunciamiento sobre la base consensual de jurisdicción. Adicionalmente, el pronunciamiento es de importancia capital para el presente escrito porque, según lo expresa la Corte, de existir duda sobre alguno de los prerrequisitos, esta debería resolverse ex officio y de manera previa al análisis del requisito consensual previsto en el artículo 36. A contrario sensu, la relevancia del pronunciamiento radica en que, aunque en nuestro caso hipotético

35 Certain Norwegian Loans (1957), p. 25; Aerial Incident of 10 August 1999 (2000), p. 24, para. 26.

36 Legality of Use of Force (2004), p. 298-9, para. 46.

37 Legality of Use of Force (2004), p. 293, para. 30.

38 Legality of Use of Force (2004), p. 299, para. 46

39 "There is no doubt that Serbia and Montenegro is a State for the purpose of Article 34, paragraph 1, of the Statute". (Destacado fuera de texto). Legality of Use of Force (2004), p. 299, para. 46 in fine. 
los Estados objetaron la jurisdicción de la Corte invocando el artículo 34 del Estatuto, de no haberlo hecho, pero existiendo dudas sobre la existencia del Estado, el análisis sobre el cumplimiento de ambos prerrequisitos por parte de la República de Andrea debía abordarse ex officio por la Corte Internacional de Justicia.

Como elemento que contribuye a la consolidación de las normas jurídicas ya expuestas, y en particular, como herramienta para la comprensión de la irrelevancia del consentimiento estatal a la hora de analizar el cumplimiento de los prerrequisitos contenidos en los artículos 34 y 35, la Corte Internacional de Justicia señaló:

"36. On this point, however, it is the view of the Court that a distinction has to be made between a question of jurisdiction that relates to the consent of party and the question of the right of a party to appear before the Court under the requirements of the Statute, which is not a matter of consent. The question is whether as a matter of law Serbia and Montenegro was entitled to seise the Court as a party to the Statute at the time when it instituted proceedings in these cases. Since that question is independent of the views or wishes of the Parties, even if they were now to have arrived at a shared view on the point, the Court would not have to accept that view as necessarily the correct one. The function of the Court to enquire into the matter and reach its own conclusion is thus mandatory upon the Court irrespective of the consent of the parties and is in no way incompatible with the principle that the jurisdiction of the Court depends on consent". (Destacado fuera de texto).

Un interrogante que de manera colateral genera el precitado Fallo y que por supuesto no puede ser resuelto conforme a este, es el del umbral o estándar que debe cumplirse para que ex ante un Estado genere dudas sobre el cumplimiento de alguno de los prerrequisitos consignados en los artículos 34 y 35 . Consentimos en que tal preocupación es menos relevante en el supuesto del numeral $1^{\circ}$ del artículo 34 pues es posible anticipar que, en casos de duda, el Estado demandado sería el más interesado en invocar la excepción preliminar respectiva.

De otra parte, no podemos pasar por alto que, más allá del texto del Fallo, las consideraciones de la Corte parecen sugerir una diferencia en el tratamiento de los prerrequisitos previstos en los artículos 34 y 35 . En efecto, aunque el acuerdo de las Partes sobre la existencia del status de Estado del demandante influenció en gran medida el pronunciamiento de la Corte en el párrafo 46 (in fine), ese consentimiento se estimó irrelevante durante el proceso de análisis del efectivo cumplimiento del prerrequisito del artículo 35. Como consecuencia, la Corte analizó de forma exhaustiva el cumplimiento objetivo del prerrequisito 
previsto en el artículo 35 pero se limitó a tomar nota del precitado acuerdo en relación con el artículo 34.

Aunque acatamos el pronunciamiento final de la Corte así como la metodología que lo precede, en nuestra consideración esta aproximación no es congruente. Lo anterior, porque la Corte ya había señalado que ambos prerrequisitos conciernen el derecho a comparecer ante la Corte y debían analizarse de manera previa a cualquier consideración en sede del artículo 36. Por lo tanto, era posible suponer que en relación con el requerimiento contenido en el artículo 34 el consentimiento estatal tampoco tenía un carácter decisivo. En nuestra posición, este diferente tratamiento no puede ser explicado a partir de una lógica jurídica consistente. El consentimiento estatal simplemente no es relevante cuando lo que se analiza son los prerrequisitos de jurisdicción.

Por esta razón, nos atrevemos a señalar que la aproximación de la Corte responde a consideraciones pragmáticas y de buena administración de justicia frente a un problema jurídico altamente complejo.

Sin perjuicio de la crítica frente a la congruencia y consistencia del pronunciamiento, en nuestra posición la aproximación de la Corte es acorde con su función judicial ${ }^{40}$. En este sentido, destacamos que aunque es posible discernir reglas de derecho internacional aplicables a la cuestión de la continua existencia del Estado pese al sumergimiento de su territorio, el asunto es altamente debatido en la doctrina internacional y la indeterminación de la base legal aplicable propiciaría una politización del debate ante la Corte.

Sobre este punto, consideramos que la decisión de la Corte en el caso de la Legalidad del Uso de la Fuerza (Serbia y Montenegro c. Bélgica) sugiere que el derecho internacional es más fácilmente discernible en relación con el prerrequisito del artículo 35. A este respecto recordemos que en la segunda frase del párrafo 36 de su pronunciamiento la Corte señaló lo siguiente:

"The question is whether as a matter of law Serbia and Montenegro was entitled to seise the Court as a party to the Statute at the time when it instituted proceedings in these cases". (Destacado fuera de texto).

Por el contrario, en relación con el artículo 34 el pronunciamiento de la Corte se caracteriza por un limitante en relación con el derecho aplicable:

"There is no doubt that Serbia and Montenegro is a State for the purpose of Article 34, paragraph 1, of the Statute". (Destacado fuera de texto).

\footnotetext{
40 Aunque como se verá en páginas posteriores, consideramos que la existencia del Estado es un asunto gobernado por el derecho internacional público, reconocemos que las discusiones sobre este particular podrían repercutir en interrogantes sobre la ausencia de un derecho aplicable y el correlativo riesgo de pronunciar un non liquet, así como en una politización innecesaria de la argumentación jurídica.
} 
El precitado párrafo genera interrogantes en relación con la viabilidad y conveniencia de emitir un pronunciamiento bajo el artículo 34 si esto implica obviar el derecho internacional general aplicable a la existencia del Estado ${ }^{41}$ y sin consultar sus consecuencias por fuera del Estatuto. Sin embargo, según anticipamos, la posición de la Corte no puede ser criticada en términos absolutos pues, a favor de la "buena administración de justicia", la Corte evade el pronunciamiento sobre un problema jurídico en donde la doctrina parece no haber decidido si la existencia del Estado "is a matter of fact" o "a matter of law":

Con el propósito de elucidar la problemática que fundamenta nuestra posición, a continuación abordamos de manera sucinta la doctrina más sobresaliente en relación con la definición del Estado (a), así como las discusiones sobre el derecho aplicable a la determinación sobre la continua existencia del Estado.

\section{a. La definición del Estado y el análisis de su subsistencia}

En la doctrina que se ha ocupado del estudio de la existencia del Estado como sujeto de derecho internacional, se ha establecido con arraigo la siguiente proposición:

"the formation of a new State is [...] a matter of fact, and not of law"42.

Aunque la manifestación proviene de quien podríamos decir es de manera prevalente un partidario de la teoría declarativa, esta afirmación tiene la capacidad de reflejar dos posturas transversalmente opuestas en lo que a la elucidación de la definición de "Estado" se refiere. Por una parte, respalda la posición dominante en relación con la existencia del Estado, esto es, la teoría declarativa; por otra, es típica de las posturas positivistas que propugnaban porque la cuestión de la creación de un Estado no fuera un asunto regulado por el derecho internacional y que, por el contrario, se resolviera única y exclusivamente por referencia al reconocimiento de los Estados ya constituidos.

La teoría declarativa del reconocimiento afirma que cuando el Estado existe de manera efectiva, el derecho y la legalidad no deben constituir parámetros de constatación sino hojas en blanco sobre las cuales se tome nota del nuevo hecho. A fortiori, esta doctrina argumenta que una vez constatada la existencia

\footnotetext{
${ }^{41}$ En principio el artículo 31 (3) (c) de la Convención de Viena sobre el Derecho de los Tratados reduce la relevancia práctica de este cuestionamiento, pues la interpretación de un tratado no puede obviar el derecho internacional general aplicable a la disposición. 1155 UNTS 331. Al respecto se sugiere analizar el fallo de la Corte Internacional de Justicia en el caso Oil Platforms, en donde el derecho inmanente a la legítima defensa bajo el artículo 51 de la Carta de las Naciones Unidas es interpretado a la luz de los requisitos de "proporcionalidad" y "necesidad", inexistentes en la Carta, pero vinculantes bajo el derecho internacional general. Oil Platforms (2003), p. 161.
}

42 Crawford (2006), p. 4. 
del Estado, las cuestiones relativas a su legalidad o ilegalidad disponen de un carácter abstracto.

En un punto medio entre la postura radical que desconoce la relevancia de los criterios de legalidad ${ }^{43}$ y los que reconocen su importancia, al menos en cierta medida, Lauterpacht señaló lo siguiente:

"The guiding juridical principle applicable to all categories of recognition is that international law, like any other legal system, cannot disregard facts and that it must be based on them provided they are not in themselves contrary to international law" ${ }^{\prime \prime 4}$.

El profesor Lauterpacht abordó la fórmula precitada indicando que, señalar que un determinado resultado no es una cuestión de hecho significa que el resultado final no puede estar sujeto a discreción arbitraria. De esta forma, el ilustre tratadista indicó que, de verificarse la existencia material del Estado, su reconocimiento emerge como un deber legal. Así se describe en su obra Recognition in International Law:

"To predicate that a given result is a question of fact is to assert that it is not a question of arbitrary discretion ... The emphasis [...] on the principle that the existence of a State is a question of fact signifies that, whenever the necessary factual requirements exist, the granting of recognition is a matter of legal duty" ${ }^{\prime 4}$.

A contrario sensu, cuando el Estado no existe en la práctica, las reglas de derecho que abogan por su existencia resultarían inútiles. En consecuencia, bajo esta teoría, la efectividad lo es todo sin que al efecto importen cuestiones sobre legitimidad o legalidad.

No obstante, Crawford señala que ni la teoría declarativa ni la teoría constitutiva ofrecen una respuesta satisfactoria frente a las realidades de la práctica moderna. Adicionalmente y según su entendimiento, la teoría declarativa confunde erróneamente los "hechos" con el "derecho" al señalar que una categoría fáctica debe suponer necesariamente una correlativa categoría jurídica. De esta forma, en términos célebremente gráficos, y con fundamento en los postulados de los eminentes tratadistas Hans Kelsen y Sir Humphrey Waldock, el eminente autor australiano indica:

"[...] A State is not a fact in the sense that a chair is a fact; it is a fact in the sense in which it may be said a treaty is a fact: that is, a legal status

\footnotetext{
${ }^{43}$ Chen afirma: "a State, if it exists in fact must exist in law". Chen (1951), p. 38.

44 Lauterpacht (1948), p. 91.

45 Lauterpacht (1948), pp. 23-24.
} 
attaching to a certain state of affairs by virtue of certain rules or practices $[\ldots]^{\prime \prime 4}$

Así las cosas, la categoría fáctica "Estado" en sentido estricto solo resulta tal como consecuencia de una regla de derecho que atañe ese estatus a esa disposición de cosas. Tal es el caso del tratado, institución que existe en el mundo físico porque su existencia como especie responde y reproduce el supuesto de hecho de una norma de derecho internacional que determina la existencia de un género así denominado.

A su turno, Crawford critica la teoría constitutiva, no en función del requerimiento de que el sujeto sea reconocido, sino en relación con el carácter exclusivamente diplomático de ese reconocimiento. En sus palabras, esta restricción suprime la posibilidad de que el reconocimiento sea efectuado bajo el rasero de categorías legales en lugar de consideraciones discrecionales ${ }^{47}$.

De otra parte, en el debate sobre la existencia del Estado, a pesar de la desaparición del Estado, no puede omitirse una referencia a la teoría sobre la "presunción de continuidad". En virtud de esta presunción, se estima que un Estado sigue existiendo a pesar de los cambios sufridos de manera temporal pero prolongada de alguno o varios de sus elementos constitutivos. El profesor James Crawford explica la presunción a la luz de los efectos de las alteraciones en el elemento del Gobierno:

"There is a strong presumption that the State continues to exist, with its rights and obligations, despite revolutionary changes in government, or despite a period in which there is no, or no effective, government. Belligerent occupation does not affect the continuity of the State, even where there exists no government claiming to represent the occupied State".

La teoría de la presunción de continuidad ha sido aplicada en respuesta a situaciones en las que el Estado ha perdido temporalmente su territorio o en donde el Gobierno ha perdido control sobre este. El caso de Somalia es representativo de un evento semejante, pues esta se vio imbuida en un estado de anarquía en el período comprendido entre el año de 1991 y el $2011^{48}$. Ante la delicada situación de Somalia fue necesaria la intervención de la ONU, que estableció un Gobierno Federal de Transición, reconocido internacionalmente

46 Crawford (2006), p. 5.

47 Crawford (2006), p. 5.

${ }^{48}$ El gobierno del Presidente Mohamed Siad Barre fue el último gobierno estable en Somalia. En el año de 1990 un grupo de oposición armada adquirió el control de la mayor parte del país. Aquel grupo se dividió en 1991 por enfrentamientos entre clanes tradicionales y así surgieron dos movimientos: el Movimiento Patriótico Somalí (MPS) en el sur, y el Movimiento Nacional Somalí (MNS) en el norte. Paralelamente el grupo "Congreso Unido Somalí" (CUS) tomó la capital del país, provocando la salida del presidente Barre. 
como el gobierno de Somalia. Al respecto, David Raic señala que el caso de Somalia pone de presente que en relación con Estados ya constituidos como tales, la presunción de continuidad favorece su existencia incluso ante la ausencia prolongada de un Gobierno efectivo:

"The Somali situation, however, seems to suggest that in the case of an established State the presumption is in favor of the continuity of statehood not only when there is a prolonged period of ineffective government but even if there is a prolonged period of "absence" of government"

De otra parte, la doctrina ha considerado que bajo la teoría de la continuidad podría excusarse el exilio temporal del Gobierno o de su población:

"If exile can be considered as a temporary problem, there is thus precedent for continuity of statehood. The presumption that such exile is temporary, however, implies that extinction could occur where ineffectiveness of a government or loss of independence continues over an extended period or becomes permanent ${ }^{\prime \prime 50}$.

Sin perjuicio de las consideraciones precedentes, el interrogante evidente es si la presunción de continuidad seguiría cobijando al Estado-Isla que como consecuencia del incremento en el nivel de las aguas pierde por completo su territorio. Tal evento no tiene precedente y, por lo tanto, las consideraciones a este respecto son por lo menos especulativas. Así mismo, surge el interrogante referido a si la existencia del Estado afectado por la pérdida del elemento territorial está condicionada por la obtención de un nuevo territorio o si por el contrario el Estado afectado continuaría existiendo en el lapso comprendido entre la desaparición del territorio y la obtención de uno nuevo que lo reemplace. Por último, si en caso de no lograr la obtención de un nuevo territorio el Estado podría subsistir sin este.

\section{b. Discusiones jurídicas sobre el derecho aplicable a la determinación sobre la continua existencia del Estado}

Actualmente existe una importante controversia en relación con el derecho aplicable a la determinación de la existencia del Estado. Los esfuerzos doctrinales por abordar la cuestión de la desaparición del Estado como consecuencia del sumergimiento de su territorio parten generalmente de la referencia al artículo 1 de la Convención de Montevideo ${ }^{51}$. Siendo claro que se trata de un instrumento

\footnotetext{
49 RAIC (2002), p. 71.

50 PARK (2011), p. 10.

51 “Artículo 1. El Estado como persona de Derecho Internacional debe reunir los siguientes requisitos: I. Población permanente.
} 
de concepción regional ${ }^{52}$, su invocación en otros escenarios internacionales ha generado discusiones sobre la aplicación consuetudinaria de sus parámetros ${ }^{53}$.

En vida, el autor Ian Brownlie consideró que el artículo 1 de la Convención de Montevideo constituía una mera enumeración que en la práctica resultaba insuficiente para estructurar una definición total de Estado. En todo caso, el eminente tratadista le reconoció al precitado artículo 1 el carácter de punto de partida en tan compleja determinación, siendo necesario en todo caso valorar otros factores para poder desarrollar una noción integral de Estado:

"This brief enumeration of criteria is often adopted in substance by jurists, but is no more than a basis for further investigation. As will be seen, not all the conditions are peremptory, and in any case further criteria must be employed to produce a working legal definition of statehood" ${ }^{\prime 24}$.

Otros tratadistas estructuran su aproximación a la Convención de Montevideo señalando que esta contiene una definición de Estado centrada en la efectividad que deja de lado consideraciones relativas a la legalidad y a la legitimidad, entre otras ${ }^{55}$. Otro sector de la doctrina ha enfocado sus esfuerzos, no en la negación de la relevancia de la Convención de Montevideo para establecer la existencia de un Estado, sino en la distinción con el proceso y normativa aplicables a la determinación de la continua existencia de una entidad ya constituida como tal. Al respecto y partiendo del análisis de instancias de práctica estatal en el siglo XX, fue posible constatar manifestaciones que sugieren que los elementos de la Convención pierden su relevancia en relación con Estados ya constituidos como tales:

"Fulfillment of the Montevideo criteria is not a guarantee of recognition as a state. However, once recognized as a state, the loss of one of more of these criteria will not necessarily deprive an entity of its statehood. In this respect, it can be said that the Montevideo criteria are not a stringent set of rules that must be fulfilled at all times" ${ }^{\prime \prime 6}$. (Destacado fuera de texto).

\footnotetext{
II. Territorio determinado.

III. Gobierno.

IV. Capacidad de entrar en relaciones con los demás Estados".

Convención de Montevideo sobre Derechos y Deberes de los Estados. Montevideo (1933).

${ }^{52}$ Los Estados parte de la Convención de Montevideo son los siguientes: Honduras, Estados Unidos, El Salvador, República Dominicana, Haití, Argentina, Venezuela, Uruguay, Paraguay, México, Panamá, Bolivia, Guatemala, Brasil, Ecuador, Nicaragua, Colombia, Chile, Perú, Cuba.

53 Opinion No 1 of the Arbitration Commission of the Peace Conference on Yugoslavia (1992), pp. 1492-1497.

54 Brownlie (2008), p. 70.

55 Grant (1999), p. 9.

56 RAYFuse y SCOtt (2012), p. 246.
} 
De esta forma, no obstante la existencia de escenarios de práctica estatal que parecieran sugerir otra cosa, notamos un importante consenso en la doctrina sobre el carácter meramente enunciativo de los elementos enumerados en la Convención de Montevideo.

De otra parte, la doctrina parece coincidir en que no existe una normativa universalmente aceptada por referencia a la cual establecer la continua existencia del Estado ${ }^{57}$. Esta situación se torna más problemática cuando se verifica que, según es defendido por un importante e influyente sector doctrinal, a la fecha el derecho internacional solo parece haber abordado supuestos de "extinción voluntaria". Al respecto, Emily Crawford y Rosemary Rayfuse evidencian que actualmente no existe en el derecho internacional una regulación del proceso de disolución de un Estado en el contexto de su total inhabitabilidad o de la total desaparición física del territorio sobre el que se asienta. Más aún, si la respuesta del derecho internacional se diera a favor de la desaparición, no existirían reglas que permitiesen determinar cuándo un Estado deja de existir a causa de la desaparición física de su territorio o de la pérdida de su población:

"International law does not yet apprehend a process of dissolution in the context of the total inhabitability or actual physical disappearance of a state's territory and no rule exist to determine whether, and if so when, a state ceases to exist by virtue of the actual physical disappearance of its population or its territory" ${ }^{\prime \prime}$.

De conformidad con las consideraciones precedentes, sostenemos que la cuestión sobre la existencia del Estado es "fundamental" al procedimiento de la Corte y debe determinarse con independencia de la constatación de una base consensual entre las partes del litigio ${ }^{59}$. Sin embargo, contrario a lo que ocurre cuando abordamos el análisis del prerrequisito previsto en el artículo 35 del Estatuto, existe una altísima indeterminación en relación con elementos esenciales del debate dentro del artículo 34, entre ellos, los elementos constitutivos del Estado, el valor del reconocimiento, el derecho aplicable a la determinación

\footnotetext{
57 SCHOISWOHL (2004).

58 Rayfuse y Scott (2012), p. 248.

${ }^{59}$ El análisis sobre la preservación de la identidad del Estado escapa al objeto de estudio del presente trabajo. Sin embargo, la modificación de la identidad del Estado generaría un problema jurídico bajo el artículo 35 del Estatuto por cuanto, de verificarse, el Estado ya no sería miembro de la Carta de las Naciones Unidas y, por lo tanto, perdería su status de parte del Estatuto hasta tanto obtenga nuevamente su membresía. En efecto, aunque el tratamiento de este asunto es casi inexistente en la doctrina internacional que aborda la cuestión de la desaparición de Estado, resulta teóricamente plausible -no por ello acertado- alegar que como consecuencia de la transformación de su territorio o la fusión con otro, un Estado perdería su identidad y por lo tanto, su Membresía en las Organización de Naciones Unidas.
} 
de la existencia del Estado y la aplicación de la teoría de la presunción de continuidad al evento sin precedente en que un Estado pierde de forma total y permanente su base territorial originaria.

Esta profunda indeterminación sobre la base legal del eventual pronunciamiento genera riesgos de una politización indebida del debate legal, no obstante la competencia ratione materiae de la Corte Internacional de Justicia para conocer del asunto ${ }^{60}$. De esta forma, consideraciones fundadas en la buena administración de justicia y los límites de la función judicial de la Corte nos llevan a defender que, en el evento en que las partes no objeten la existencia de uno de los Estados parte del procedimiento, el asunto no debería ser abordado por la Corte motu proprio aun tratándose de un verdadero requisito de jurisdicción.

\section{La viabilidad de la delimitación marítima en eventos en donde al menos uno de los Estados perdería su territorio con posterioridad al fallo de delimitación}

\subsection{Las consecuencias del sumergimiento y la inhabitabilidad en el estatus jurídico del territorio de los Estados-Islas}

Con independencia de la capacidad del derecho internacional para ofrecer respuestas directas a fenómenos contemporáneos como el cambio climático, las consecuencias del hundimiento o de la inhabitabilidad de una isla se encuentran reguladas por el derecho internacional convencional -en la Convención de las Naciones Unidas sobre el Derecho del Mar-y por el derecho internacional consuetudinario ${ }^{61}$.

A este respecto, recordemos que en relación con el régimen legal aplicable a las islas el artículo 101 de la Convención sobre el Derecho del Mar prevé:

"Artículo 121

Régimen de las islas

1. Una isla es una extensión natural de tierra, rodeada de agua, que se encuentra sobre el nivel de esta en pleamar.

\footnotetext{
${ }^{60}$ Sobre la competencia de la Corte Internacional de Justicia en relación con asuntos con un trasfondo político incluso más amplio que el del debate legal, así como en relación con temáticas atribuidas de forma primaria a otros órganos de las Naciones Unidas ver: Questions of Interpretation and Application of the 1971 Montreal Convention arising from the Aerial Incident at Lockerbie (1998), p. 23, para. 36; United States Diplomatic and Consular Staff in Tehran (1980), p. 20, para. 37.

${ }^{61}$ En su Fallo de 19 de noviembre de 2012 en el Diferendo Territorial y Marítimo entre Nicaragua y Colombia la Corte Internacional de Justicia tomó nota del acuerdo entre las partes sobre el carácter consuetudinario del artículo 101 de la Convención sobre el Derecho del Mar en lo relativo al régimen jurídico de las islas. Territorial and Maritime Dispute (2012), p. 624, p. 673, para. 138.
} 
2. Salvo lo dispuesto en el párrafo 3, el mar territorial, la zona contigua, la zona económica exclusiva y la plataforma continental de una isla serán determinados de conformidad con las disposiciones de esta Convención aplicables a otras extensiones terrestres.

3. Las rocas no aptas para mantener habitación humana o vida económica propia no tendrán zona económica exclusiva ni plataforma continental". (Destacado fuera de texto).

El análisis en el contexto relevante al presente escrito debe ser complementado con una referencia a la regulación internacional de las elevaciones de bajamar. Al efecto, se trascribe a continuación el texto del artículo 13 de la Convención sobre el Derecho del Mar:

"1. Una elevación que emerge en bajamar es una extensión natural de tierra rodeada de agua que se encuentra sobre el nivel de ésta en la bajamar, pero queda sumergida en la pleamar. Cuando una elevación que emerge en bajamar esté total o parcialmente a una distancia del continente o de una isla que no exceda de la anchura del mar territorial, la línea de bajamar de esta elevación podrá ser utilizada como línea de base para medir la anchura del mar territorial.

2. Cuando una elevación que emerge en bajamar esté situada en su totalidad a una distancia del continente o de una isla que exceda de la anchura del mar territorial, no tendrá mar territorial propio".

De conformidad con la normativa en comento, es posible señalar que el cambio climático y el incremento del nivel del mar que le sucede generan los siguientes escenarios relevantes para los diferentes supuestos de delimitación marítima:

\section{a. La isla, base territorial del Estado-Isla, se torna inhabitable pero se mantiene a flote en pleamar}

En este supuesto, la isla habrá perdido uno de los atributos que de conformidad con el artículo 101 de la Convención de Naciones Unidas sobre el Derecho del Mar le permite ser titular de una plataforma continental y zona económica exclusiva propia, el de la habitabilidad. Sin embargo, no podemos pasar por alto que el numeral $3^{\circ}$ del artículo 121 antes transcrito también menciona la aptitud para sostener una vida económica propia. Según lo pone de presente Dubner, los criterios de habitabilidad y vida económica, aunque con precedentes previos en la práctica internacional, no habían sido consagrados en ningún instrumento convencional previo a la Convención sobre el Derecho del Mar de 1982. En efecto, la definición de esta formación marítima en el artículo 10, numeral $1^{\circ}$ 
del Convenio de Ginebra de 1958 sobre Mar Territorial y Zona Contigua omite cualquier referencia semejante ${ }^{62}$.

Aunque la doctrina destaca el carácter radical de la modificación efectuada ${ }^{63}$, es así mismo crítica en relación con la indeterminación de las nociones de inhabitabilidad y vida económica en el numeral $3^{\circ}$ antes aludido ${ }^{64}$. En efecto, lejos de contar con una definición autorizada y consistente sobre el alcance de los criterios ya mencionados, solo es posible evidenciar tímidas aproximaciones doctrinales que como la de Brown relacionan la habitabilidad con la existencia de agua potable ${ }^{65}$. Por su parte, la Resolución No. 4 de la Conferencia Imperial de 1923, documento que estableció las pautas de la política exterior de Gran Bretaña en relación con los límites de sus aguas territoriales, interpretó las palabras "capable of use or habitation" como un compromiso para que se considerase como isla a aquella que podía mantener su utilidad sin ningún tipo de interferencia artificial ${ }^{66}$.

Sin perjuicio de lo anterior, la interpretación del artículo 121 de la Convención sobre el Derecho del Mar a la luz de los criterios consuetudinarios de interpretación de los tratados nos permite arribar a conclusiones relevantes para nuestro análisis. En efecto, con base en el entendimiento del sentido literal de los términos empleados, por supuesto en buena fe y de conformidad con el objeto y fin de la Convención, notamos que el numeral $3^{\circ}$ del artículo 121 precitado utiliza la partícula "o" para enlistar los criterios sin los cuales una "extensión natural de tierra rodeada de agua, que se encuentra sobre el nivel de esta en pleamar", únicamente es titular de un mar territorial de 12 millas náuticas. De esta forma, es posible colegir que la aptitud para mantener la habitación humana y la vida económica son criterios alternativos y no cumulativos. Como corolario, si a pesar de haber perdido su aptitud para ser habitada, la isla sigue siendo idónea para mantener una vida económica propia, esta seguirá siendo titular de una plataforma continental y una zona económica exclusiva ${ }^{67}$.

En nuestra posición, esta posibilidad no es remota porque la explotación de recursos naturales, renovables y no renovables, así como el potencial para el turismo de los Estados-Isla son fácilmente defendibles como actividades económicas para cuya viabilidad no es imprescindible una presencia humana permanente o continua.

${ }^{62}$ Dubner (1995), p. 300.

63 Brown (1994), p. 149.

${ }^{64}$ DiAz et al. (2007), p. 533.

${ }^{65}$ Brown (1994), p. 150.

${ }^{66}$ Imperial Conference, Report of Inter-Departmental Committee on the Limits of Territorial Waters (1923), p. 5.

67 DUBNeR (1995), p. 300. 


\section{b. La isla, base territorial del Estado-Isla, se torna inhabitable, pero además deja de mantenerse a flote en pleamar}

En este escenario, plausible según avancen los años y el incremento de las aguas, ya no será posible seguir hablando de "isla" para referirse a la formación natural de tierra, la cual, sin importar su extensión, ahora constituirá simplemente una formación de baja mar. En este punto resulta interesante recordar que el tamaño de la isla es irrelevante en relación con las consideraciones sobre los espacios marítimos. Esta situación beneficia a la isla en el sentido que, como lo ejemplifica la decisión de la Corte Internacional de Justicia en relación con la isla colombiana de "Quitasueño" 32 (QS32), con una extensión de poco más de un metro cuadrado, sin importar que tan pequeña sea la isla, esta tendrá derecho a un mar territorial de 12 millas si permanece a flote en pleamar ${ }^{68}$. A contrario sensu, sin importar qué tan grande sea la porción de tierra, si solo permanece a flote en bajamar, constituirá una elevación de baja mar para todos los efectos.

Sobre este particular, Dubner recuerda que durante la Conferencia de Codificación del Derecho Internacional de La Haya de 1930, muchos Gobiernos sostuvieron que las islas geográficas solo podrían disponer de un estatus legal, es decir, ser titulares de un mar territorial, si se comprobaba su habitabilidad. Esta posición sería derrotada en el Sub-Comité Il de la Segunda Comisión (Aguas Territoriales), en donde se precisó que toda formación de tierra rodeada por mar responde a la noción de isla en sentido legal si permanece a flote en pleamar ${ }^{69}$. Una posición idéntica es discernible en los comentarios de la Comisión de Derecho Internacional al artículo 10 del Convenio de $1958^{70}$.

De conformidad con las consideraciones expuestas, es posible colegir que la consecuencia inmediata del total sumergimiento del territorio de un EstadoIsla es la pérdida del estatus jurídico atribuido a las "islas". Al respecto, resulta ilustrativo destacar que en el Diferendo Territorial y Marítimo en el Mar Caribe entre Nicaragua y Honduras, las Partes acordaron de forma rápida y pacífica que, de conformidad con el numeral $1^{\circ}$ del artículo 121 de la Convención sobre el Derecho del Mar, el Cayo Media Luna, actualmente sumergido, ya no constituía una isla a la luz del derecho internacional. A su turno, la discusión más intensa se generó en relación con la prueba sobre el sumergimiento del Cayo Logwood en pleamar:

"143. During the proceedings, two other cays were mentioned: Logwood Cay (also called Palo de Campeche) and Media Luna Cay. In response

\footnotetext{
68 Territorial and Maritime Dispute (2012), pp. 644 y ss. paras. 36 y ss.

${ }^{69}$ DUBNeR (1995), p. 300.

70 ILC, Report of the International Law Commission Covering the Work of its Eight Session (1956), pp. 16-17.
} 
to a question put by Judge ad hoc Gaja to the Parties in the course of the oral proceedings as to whether these cays would qualify as islands within the meaning of Article 121, paragraph 1, of UNCLOS, the Parties have stated that Media Luna Cay is now submerged and thus that it is no longer an island. Uncertainty prevails in the case of Logwood Cay's current condition: according to Honduras it remains above water (though only slightly) at high tide; according to Nicaragua, it is completely submerged at high tide" ${ }^{\prime \prime 1}$.

Por su parte, la inhabitabilidad del territorio de un Estado-Isla, además del fenómeno migratorio que genera, tiene por consecuencia la pérdida de espacios marítimos, pues una isla inhabitable es equiparable a una roca, según el régimen previsto en el numeral $3^{\circ}$ artículo 121 supra ${ }^{72}$.

Sin perjuicio de las consecuencias jurídicas de los anteriores escenarios, el presente escrito intenta abordar un supuesto más complejo, al menos desde una perspectiva litigiosa: aquél en donde un tribunal internacional conoce de una controversia de delimitación marítima en donde uno de los Estados aún dispone de territorio que puede generar derechos marítimos, pero existe evidencia científica que acredita que ese territorio dejará de estar a flote con posterioridad a la emisión del fallo de delimitación ${ }^{73}$. La pregunta a resolver versa sobre la viabilidad de la delimitación en un escenario en donde los puntos de base de una de las partes dejarán de existir irremediablemente.

\subsection{La viabilidad de la delimitación marítima ante el inminente sumergimiento de los puntos de base}

Los artículos 4 a 14 de la Convención de las Naciones Unidas sobre el Derecho del Mar de 1982 consagran métodos que permiten a los Estados medir la anchura del mar territorial, según sus especiales características geográficas ${ }^{74}$.

71 Territorial and Maritime Dispute between Nicaragua and Honduras in the Caribbean Sea (2007), p. 704 , para.143.

72 La inhabitabilidad de la isla como consecuencia del cambio climático ya ha sido advertida por el Panel Intergubernamental sobre el Cambio Climático, el cual proyecta desplazamientos forzados por el incremento del nivel del mar, los climas extremos y las altas temperaturas. PARK (2011), p. 13.

${ }^{73}$ Los problemas jurídicos estrictamente procedimentales de este supuesto ya fueron abordados en el Título II (2) en relación con los límites de la función judicial de la Corte, acápite en el que se esbozaron varios argumentos que favorecen un pronunciamiento de la Corte, entre ellos, la existencia de un supuesto fáctico actual que prima facie desarrolla el contenido de una norma de derecho internacional y que por lo tanto, permite a la Corte resolver el asunto conforme al silogismo clásico. Así mismo, se aludió al pronunciamiento de la Corte en el Diferendo Territorial y Marítimo (Nicaragua c. Colombia) en el que se aludió a la función social del proceso de delimitación.

${ }^{74}$ El trabajo de la Oficina de Asuntos Oceánicos y del Derecho del Mar de las Naciones Unidos resalta por su sistematicidad y análisis de la práctica estatal relevante. Office for Ocean Affairs and the Law of 
Aunque las fórmulas varían desde aquellas que sugieren la fijación de una línea de base normal, una línea de base recta, hasta el uso del lado del arrecife que da al mar, entre otras, estas guardan dos puntos en común, a saber, la referencia a la línea de baja mar y la referencia a la cartografía a gran escala reconocida oficialmente por el Estado ribereño ${ }^{75}$. En este sentido, es posible anticipar que si el cambio climático se manifiesta en el incremento del nivel de las aguas, en muchos Estados los puntos de base históricamente fijados en su cartografía oficial se encuentren sumergidos actualmente o quedarán sumergidos en fechas no muy lejanas.

El precitado escenario no genera problemas únicamente en relación con la fijación de límites, sino también en el establecimiento de fronteras marítimas ya sea por mutuo acuerdo o por decisión de un tribunal internacional ${ }^{76}$. En efecto, según lo prevé el artículo 15 de la precitada Convención sobre el Derecho del Mar, la regla general para la delimitación del mar territorial es la fijación de una línea media que tendrá como punto de referencia "las líneas de base a partir de las cuales se mida la anchura del mar territorial de cada uno de esos Estados". Sin embargo, el precitado artículo también prevé que:

"No obstante, esta disposición no será aplicable cuando, por la existencia de derechos históricos o por otras circunstancias especiales, sea necesario delimitar el mar territorial de ambos Estados en otra forma". (Destacado fuera de texto).

El problema jurídico en comento fue abordado in extenso por el Tribunal Arbitral constituido bajo el Anexo VII de la Convención sobre el Derecho del Mar que resolvió el Arbitraje sobre la Frontera Marítima en la Bahía de Bengala entre Bangladesh e India ${ }^{77}$. En efecto, con ocasión de la delimitación del mar

the Sea, Baselines: An Examination of the Relevant Provisions of the United Nations Convention on the Law of the Sea (1989). Disponible en: http://www.un.org/depts/los/doalos_publications/publicationstexts/ The\%20Law\%20of\%20the\%20Sea_Baselines.pdf [visitado el 28/06/2014].

75 La Convención exige que la línea de baja mar se designe con el signo apropiado en las "cartas reconocidas oficialmente por el Estado ribereño". Los signos describen, inter alia, formaciones de bajamar, arrecifes, parches de arrecife.

${ }^{76}$ Aunque escapa al objeto específico de estudio del presente trabajo, aprovechamos este pie de página para proponer una utilización más precisa de los términos "límite" y "frontera" marítima. En este sentido, apoyamos el sector doctrinal que defiende el uso del término "límite marítimo" para referirse a la demarcación unilateral que el Estado hace en sus áreas marítimas, cuando estas no se superponen o afectan los espacios marítimos de otros Estados. Dupuy y VIGNes (Eds.) (1991), p. 426. De otra parte, apoyamos el uso del término "frontera" en relación con espacios sometidos a delimitación, por mutuo acuerdo o adjudicación internacional, considerando que el atributo de permanencia y estabilidad también es predicable de las fronteras marítimas.

77 Award in the matter of the Bay of Bengal Maritime Boundary Arbitration between The People's Republic of Bangladesh and the Republic of India (2014). 
territorial entre las partes y en sus consideraciones en relación con los puntos de base seleccionados por ellas, el Tribunal abordó de manera directa y exhaustiva el escenario en donde los puntos de base de uno de los Estados estaban destinados a desaparecer como consecuencia del cambio climático.

En este caso, tras indicar que el desacuerdo entre las partes respecto de la metodología de delimitación aplicable a cada espacio marítimo no había sido óbice para que las partes propusieran sus respectivos puntos de base, el Tribunal puso de presente aquellos efectivamente propuestos para la construcción o trazado de la línea de equidistancia provisional ${ }^{78}$. Así mismo, el Tribunal indicó que la cuestión de los puntos de base sugeridos hacía parte de la disputa ${ }^{79}$.

Bangladesh había objetado algunos de los puntos de base propuestos por India argumentando su inexistencia como formaciones de bajamar dada la imposibilidad de constatar su existencia en la visita efectuada al área. Según lo observó el Tribunal, el alegato en relación con los puntos I-1 y I-2, localizados en South Talpatty/NewMoore Island, fueron particularmente agudos y se dirigieron a demostrar su inexistencia como consecuencia del sumergimiento y la ausencia de evidencia en imágenes satelitales. Sin perjuicio de las precitadas consideraciones, Bangladesh planteaba una posición de fondo más radical: que la inestabilidad de la zona era tal que hacía inviable la identificación de puntos de base y a fortiori la construcción de una línea provisional equidistante. En particular, Bangladesh aludió a los efectos del cambio climático y el incremento del nivel del agua. El alegato es resumido por el Tribunal, en los siguientes términos:

"213. Bangladesh argues that the instability of the coastline is a major factor weighing against the use of the provisional equidistance/relevant circumstances method, in particular in view of the potential effect of climate change and sea level rise in the Bay of Bengal. Within a few years, Bangladesh submits, the low tide elevations chosen by India will likely have changed or disappeared. Even the coastal locations of the base points chosen by Bangladesh will probably be submerged". (Destacado fuera de texto).

Por esta razón, Bangladesh alegaba que debía exceptuarse la metodología general prevista en el artículo 15 supra y, por lo tanto, el mar territorial debía delimitarse mediante el trazado de un ángulo de bisectriz de 180 grados $^{80}$.

\footnotetext{
78 Award in the matter of the Bay of Bengal Maritime Boundary Arbitration (2014), pp. 57-58 paras. 193-4.

79 Award in the matter of the Bay of Bengal Maritime Boundary Arbitration (2014), p. 58, para. 195.

${ }^{80}$ Award in the matter of the Bay of Bengal Maritime Boundary Arbitration between The People's Republic of Bangladesh and the Republic of India (2014), p. 61, para. 208.
} 
El Tribunal recordó que la delimitación del mar territorial debe efectuarse de conformidad con los puntos más protuberantes de las costas que estén más próximos al área a delimitar, por ser estos los que reflejan la dirección general de la costa ${ }^{81}$. A continuación, el Tribunal desestimaría los argumentos de Bangladesh en relación con los efectos del cambio climático en el incremento del nivel de las aguas como justificativo para exceptuar el método de equidistancia/circunstancias relevantes ${ }^{82}$.

"214. In the view of the Tribunal, this argument is not relevant. The issue is not whether the coastlines of the Parties will be affected by climate change in the years or centuries to come. It is rather whether the choice of base points located on the coastline and reflecting the general direction of the coast is feasible in the present case and at the present time. As the International Court of Justice stated in the Black Sea case:

'In this respect, the Court observes that the geometrical nature of the first stage of the delimitation exercise leads it to use as base points those which the geography of the coast identifies as a physical reality at the time of the delimitation. That geographical reality covers not only the physical elements produced by geodynamics and the movements of the sea, but also any other material factors that are present'. (Judgment, I.C.J. Reports 2009, p. 61, at p. 106, paragraph 131)".

La determinación del Tribunal evidencia su entendimiento sobre el valor normativo que debe -o que no debe- atribuirse en el presente a los inevitables efectos futuros del cambio climático en las formaciones marítimas de baja altura. Sobre este punto, el Tribunal indicó:

"215. The Tribunal is concerned with the "physical reality at the time of the delimitation" (ibid.). It need not address the issue of the future instability of the coastline". (Destacado fuera de texto).

Según será desarrollado en mayor medida en el acápite de conclusiones del presente escrito, en nuestra consideración este pronunciamiento puede y debe inspirar las políticas públicas y estrategias diplomáticas de los EstadosIslas cuyos territorios enfrentan el riesgo de desaparecer como consecuencia del incremento constante del nivel del mar.

${ }^{81}$ Award in the matter of the Bay of Bengal Maritime Boundary Arbitration (2014), p. 62, para. 211. Maritime Delimitation in the Black Sea (2009), p. 105, para. 127.

82 Bangladesh señaló que dentro de pocos años, las formaciones de bajamar escogidas por India, e incluso las suyas, estarían sumergidas. Ver para. 213. 
A continuación, demostrando que en relación con la estabilidad de las fronteras internacionales cualquier distinción es artificiosa ${ }^{83}$, el Tribunal señaló que la función de la frontera establecida en el proceso de delimitación no es otra que asegurar que las relaciones entre los Estados concernidos sean pacíficas con el pasar de los años y no solamente por un corto período de tiempo. Por su relevancia se transcriben in extenso las consideraciones del tribunal:

"216. The Tribunal notes that maritime delimitations, like land boundaries, must be stable and definitive to ensure a peaceful relationship between the States concerned in the long term. As the International Court of Justice noted in its decision in the Temple of Preah Vihear case, "[i]n general, when two countries establish a frontier between them, one of the primary objects is to achieve stability and finality" (Merits, Judgment of 15 June 1962, I.C.J. Reports 1962, p. 6 atp. 34). The same consideration applies to maritime boundaries.

217. In the view of the Tribunal, neither the prospect of climate change nor its possible effects can jeopardize the large number of settled maritime boundaries throughout the world. This applies equally to maritime boundaries agreed between States and to those established through international adjudication ${ }^{\prime 24}$. (Destacado fuera de texto).

Los párrafos siguientes en el razonamiento del Tribunal defienden la prevalencia de la realidad actual por sobre consideraciones sobre el futuro próximo o remoto de las formaciones marítimas. Al efecto, se invoca la importancia económica de los recursos de la plataforma continental y se apela a consideraciones pragmáticas. Nuevamente, por estimarse altamente relevante para el lector, se traducen los párrafos relevantes en su totalidad:

"218. The importance of stable and definitive maritime boundaries is all the more essential when the exploration and exploitation of the resources of the continental shelf are at stake. Such ventures call for important investments and the construction of off-shore installations, including those governed by the Convention in Parts VI and XI and in article 60. Bangladesh rightly points out the importance of such resources to a heavily populated State with limited natural resources. In the view of the Tribunal, the sovereign rights of coastal States, and therefore the maritime

${ }^{83}$ Para una discusión litigiosa que pone en evidencia que la "permanencia" y "estabilidad" no son atributos exclusivos de las fronteras terrestres sino también de las marítimas, ver: Delimitation of the Maritime Boundary in the Gulf of Maine Area (1984), p. 265 y Case concerning the delimitation of maritime boundary between Guinea-Bissau and Senegal (1989), pp. 144 y ss, para. 63 y ss.

${ }^{84}$ Award in the matter of the Bay of Bengal Maritime Boundary Arbitration between The People's Republic of Bangladesh and the Republic of India (2014), p. 63, paras. 216-7. 
boundaries between them, must be determined with precision to allow for development and investment. The possibility of change in the maritime boundary established in the present case would defeat the very purpose of the delimitation" ${ }^{\prime \prime 5}$. (Destacado fuera de texto).

Posteriormente, el Tribunal apela a los avances científicos actuales para señalar que el problema del sumergimiento de los puntos de base, aunque teórica e históricamente relevante, es de fácil solución en la actualidad pues la tecnología satelital permite ubicar de forma sencilla puntos geodésicos en el mar:

"The Tribunal further notes that the problem has been greatly simplified by modern technology. Whereas it was important in the past to rely on permanent coastal features for the identification of boundaries at sea, satellite navigation systems now allow users of the oceans to easily locate any geodetic point without resorting to the actual physical features used at the date of delimitation" ${ }^{\prime \prime 6}$. (Destacado fuera de texto).

Nuevamente, las consideraciones del Tribunal resultan de un gran valor práctico para Estados-Islas enfrentados a un no tan hipotético escenario de desaparición de su territorio como consecuencia del incremento del nivel del mar. La posición del Tribunal es clara: no existe diferencia entre los justificantes de la estabilidad de las fronteras terrestres y las marítimas -establecidas por mutuo acuerdo o por decisión judicial-. Según lo señala y reitera enérgicamente el Tribunal, la estabilidad es el objeto mismo del procedimiento de delimitación, siendo esta una herramienta que asegura la paz y seguridad en la región. Por lo tanto, la posibilidad de cambio en el límite marítimo establecido "frustraría el propósito mismo de la delimitación". Así mismo, el Tribunal destacó que siendo clara la relevancia de la estabilidad en la delimitación marítima, esta se torna aún más esencial en relación con la exploración y explotación de los recursos de la plataforma continental, pues conociéndose con claridad los límites de los derechos soberanos sobre esta, el Estado costero podrá autorizar los respectivos proyectos de inversión que promuevan su crecimiento económico y desarrollo.

De esta forma, el Tribunal en el caso de Bangladesh e India resolvió de forma afirmativa la cuestión sobre la viabilidad de la delimitación marítima en escenarios de inestabilidad geográfica tan extrema como los propiciados por el cambio climático. En consideración de los autores, la decisión final del Tribunal es afortunada, de forma llana y simple, porque ante las diferentes posibilidades de definición, el Tribunal escogió aquella que favorecía la paz y el mantenimiento del orden de las fronteras marítimas en un escenario susceptible de generar caos.

85 Award in the matter of the Bay of Bengal Maritime Boundary Arbitration (2014), p. 63, paras. 216-7.

${ }_{86}$ Award in the matter of the Bay of Bengal Maritime Boundary Arbitration between The People's Republic of Bangladesh and the Republic of India (2014), p. 63, para. 218. 
Así mismo, consideramos que los argumentos que soportan esa decisión disponen de la consistencia jurídica suficiente para ser aplicados de manera convincente en otros supuestos fácticos. En efecto, la decisión final del Tribunal no se limita a reproducir decisiones judiciales previas en relación con la estabilidad de las fronteras, y por el contrario, las acompaña con consideraciones de carácter técnico, pragmático y otros que, aunque económicos ab initio, se fundamentan en una preocupación por la supervivencia misma del Estado y de su población. Finalmente, se trata de un pronunciamiento que cumple con una función social verificable pues, al dar cuenta de una dificultad moderna, se vale de las herramientas que la misma modernidad ofrece para resolverla de manera satisfactoria a los intereses de la comunidad internacional.

\section{Conclusiones}

Contrario a lo expresado por los Estados demandados de nuestro caso hipotético, la decisión de un Estado Isla amenazado por el cambio climático de acudir ante la Corte Internacional de Justicia con el propósito de que las fronteras marítimas con sus Estados vecinos se resuelvan con efectos de cosa juzgada no es "sorpresiva", "mezquina", "ilegal" y "torpe".

En efecto, el acceso a la Corte Internacional de Justicia o ante cualquier otro tribunal es consistente con la obligación de los Estados de resolver sus controversias a través de mecanismos pacíficos, razón por la cual no constituye una actuación inamistosa. No se trata tampoco de una actuación torpe porque como lo demuestra la decisión del Tribunal en el caso entre Bangladesh e India, la delimitación marítima no se ve frustrada por el sumergimiento futuro de los puntos de base y, por el contrario, cuando esta se gesta en sede de adjudicación tiene como resultado un fallo con fuerza de cosa juzgada y que, por lo tanto, no puede ser alterado por el sumergimiento posterior de una parte o incluso de la totalidad del territorio estatal.

Sobre este último punto debemos señalar que los efectos de la cosa juzgada de las decisiones de la Corte Internacional de Justicia, esto es, su carácter vinculante, final y definitivo, solo podrían verse afectados a través del recurso de revisión previsto en el artículo 61 de su Estatuto, curso de acción altamente reglado y restringido desde su concepción ${ }^{87}$.

Sin perjuicio de lo anterior, el carácter sorpresivo del recurso ante la Corte Internacional de Justicia, o ante otro tribunal internacional, no vicia o deslegitima el uso del recurso en sí mismo. En primer lugar, porque por regla general el acceso a la Corte no está condicionado a la aproximación diplomática

${ }^{87}$ Sobre la precisión que el hecho no debe ocurrir con posterioridad al fallo cuya revisión se solicita, ver: Application for Revision of the Judgment of 11 July 1996 in the Case concerning Application of the Convention on the Prevention and Punishment of the Crime of Genocide (2003), p. 30. 
previa entre las partes, inter alia, a través de la negociación o la conciliación ${ }^{88}$, requiriéndose entonces una referencia expresa para que una actuación tal sea exigible. En segundo lugar y en relación con el punto anterior, basta con recordar que los Estados son libres de condicionar su consentimiento a la jurisdicción de la Corte al agotamiento previo de negociaciones en relación con la materia objeto de la disputa ${ }^{89}$. Adicionalmente, en ausencia de un limitante semejante, la demanda ante la Corte, cuando ambos han manifestado inequívocamente su consentimiento a la jurisdicción, ofrece una ventaja diplomática importante y una alternativa en aquellos casos en donde la negociación de un tratado no se observa factible, o las prolongaciones típicas de las negociaciones simplemente no lo hacen atractivo ${ }^{90}$.

De otra parte, la posición de los autores es que la decisión del Tribunal constituido bajo el Anexo VII de la Convención sobre el Derecho del Mar en el Arbitraje sobre la Frontera Marítima en la Bahía de Bengala entre Bangladesh e India puede y debe servir de directriz y complementar, desde lo jurídico, los actuales esfuerzos que los Estados-Islas despliegan en los planos políticos y diplomáticos.

Entre estas actuaciones históricas de los Estados-Islas se destaca la del Presidente de las Maldivas, Mohamed Nasheed ${ }^{91}$, quien se sumergió bajo el mar junto con sus Ministros a efectos de firmar una declaración que establecía el compromiso de unirse en un esfuerzo global para contrarrestar el aumento de la temperatura del planeta ${ }^{92}$. En esta iniciativa se hizo énfasis en que, de no contrarrestarse el incremento de temperatura provocado por el cambio climático, las Maldivas se convertirían en un territorio inhabitable a finales del siglo XXI. Así mismo, se proyectó que el 15\% de la capital Malé estaría sumergida para el 2025 y el 50\% para el 210093. En 1987 el Presidente Abdul Gayoom ya se había pronunciado al respecto ante la Asamblea General de

\footnotetext{
88 Armed Activities on the Territory of the Congo (New Application: 2002), (2006), p. 6.

${ }^{89} \mathrm{Al}$ respecto ver el artículo 21 de la Convención Internacional sobre la Eliminación de Todas las Formas de Discriminación Racial (1965).

${ }^{90}$ En su fallo en el caso de la Plataforma Continental del Mar del Norte, la Corte Internacional de Justicia citó la jurisprudencia previa de la Corte Permanente de Justicia Internacional para señalar que "the judicial settlement of international disputes 'is simply an alternative to the direct and friendly settlement of such disputes between the parties' (P.C.I.J., Series A, NN22, at p. 13)". North Sea Continental Shelf (1969), p. 87.

91 Las Maldivas tienen una elevación promedio de 1,5 metros sobre el nivel del mar y, por lo tanto, una elevación de las aguas de tan sólo 0,49 metros implicaría que gran parte del archipiélago que conforma este Estado resulte inundada para el 2100. KNOx (2009), p. 480.

92 Olivia Lang, Maldives Leader in Climate Change Stunt, BBC News, Oct. 17/2009, http://news.bbc. co.uk/2/hi/8312320.stm [visitado el 12/12/2014].

93 Gagain (2012), p. 80.
} 
las Naciones Unidas afirmando que el incremento del nivel del mar tendría como efecto: "the death of a nation". Posteriormente, un grupo de pequeños Estados-Isla conformaron una organización denominada "Association of Small Islands States", por medio de la cual reclamaban la reducción de las emisiones de gases de efecto invernadero.

Sin perjuicio de lo anterior, las Maldivas han planeado medidas de adaptación a largo plazo consistentes, inter alia, en movilizar un gran número de sus habitantes a islas más grandes como parte de lo que denominan "Safe Islands Projects". Este proyecto va acompañado de la construcción de islas artificiales de mayor elevación y el establecimiento de un fondo financiero para la compra de nuevas tierras con el fin de relocalizar a la población. También fue construido "The Great Wall Of Malé", un muro alrededor de la capital que busca mitigar los efectos de las inundaciones

En este contexto, los Estados-Isla, que día a día pierden la batalla frente al mar, pueden hacer uso de la delimitación marítima para hacer valer en el futuro y de manera estable y permanente los puntos de base hoy fijados en las cartas de gran escala que reconocen como oficiales. Se trata entonces de que los Estados-Isla introduzcan en la defensa jurídica de sus derechos marítimos el argumento de la estabilidad de las fronteras marítimas. Para este efecto, los Estados-Isla pueden hacer suyas las consideraciones del Tribunal que resolvió la controversia entre Bangladesh e India, el cual encontró en la necesidad de garantizar a los Estados el acceso, disfrute y disposición de sus recursos naturales, un argumento poderoso a favor de la viabilidad de la delimitación en escenarios de altísima inestabilidad. Así mismo, los argumentos del Tribunal sobre los avances de la tecnología y su utilidad para ubicar coordenadas geográficas pueden usarse para enfrentar las preocupaciones de quienes prefieren puntos de base visibles.

En todo caso, la decisión de un Estado de acudir ante la Corte Internacional de Justicia genera importantes obstáculos procedimentales que deberán ser solventados de manera previa. En primer lugar, es necesario verificar que todos y cada uno de los Estados concernidos ha consentido a la jurisdicción de la Corte sobre la materia objeto de disputa. En segundo lugar, un Estado-Isla en una situación tan precaria y extrema como la que enfrentaba la hipotética República de Andrea al momento de presentar su Solicitud, deberá estar preparada para afrontar un eventual debate en relación con los denominados prerrequisitos de jurisdicción. En efecto, aunque aún no ocurre en la práctica de la Corte, sigue siendo teóricamente viable que un demandante refute el estatus de "Estado" de su contraparte y, con ello, su derecho a comparecer ante la Corte en los términos del artículo 34 del Estatuto. En todo caso, como ya vimos, a pesar de que los prerrequisitos estatutarios contenidos en los artículos 34 y 35 no dependen del consentimiento estatal, la Corte Internacional de Justicia 
parece estar dispuesta a obviar la cuestión sobre la existencia o desaparición del Estado en el evento en que no evidencie la existencia de un debate entre las partes a este respecto.

Según fue expuesto por los autores, en ausencia de un fundamento jurídico, la aproximación de la Corte parece responder a consideraciones pragmáticas y al propósito de no propiciar una politización innecesaria del debate jurídico. Nuestra posición no es del todo crítica frente a la aproximación de la Corte pues, como fue analizado, la falta de claridad del derecho internacional en este ámbito no favorece la predictibilidad y, por lo tanto, la decisión de no abordar este debate está acorde con los límites de la función judicial.

\section{Bibliografía CitADA}

\section{Libros o CAPÍtULOS DE LIBRO}

Brown, E.D. (1994): The International Law of the Sea, Introductory Manual (Aldershot, Dartmouth), pp. 149-150.

Brownlie, Ian (2008): Principles of Public International Law, $7^{\text {th }}$ edition (Oxford, Oxford University Press).

CHEN, Ti-Chiang (1951): The International Law of Recognition with special reference to Practice in Great Britain and the United States (London, Stevens \& Sons Limited).

Crawford, James (2006): The Creation of States, $2^{\text {nd }}$ ed. (Oxford, Oxford University Press).

Dupuy, René Jean y Vignes, Daniel (1991), A Handbook on the New Law of the Sea (Hingham Massachusetts, Kluwer).

Fuentes, Ximena (2014): "Latin American States and the International Court of Justice", en: KuEIN Nataly (ed), Litigating International Law Disputes, Weighing the Options (Cambridge, Cambridge University Press).

Grant D., Thomas (1999): The recognition of States: Law and Practice in Debate and Evolution (Westport, Greenwood Publishing Group).

LAUTERPACHT, Hersch (1948): Recognition in International Law (Cambridge, Cambridge University Press).

RAIC, David (2002): Statehood and the Law of Self-determination (The Hague, Kluwer Law International).

SHANy, Yuval (2014): Assessing the Effectiveness of International Courts (Oxford, Oxford University Press).

Scholsworl, Michael (2004): Status and (Human Rights) Obligations of nonrecognized De Facto Regimes in International Law: The case of Somaliland (Leiden, Boston, Martinus Nijhoff Publishers). 
RAYFusE, Rosemary y Scott, Shirley V. (eds.) (2012): International Law in the Era of Climate Change (Northampton Massachusetts, Edward Elgar Publishing Limited).

\section{Artículos académicos}

AtapatTy, Sumudu (2009-2010): "Climate Change, Human Rights, and Forced Migration: Implications for International Law", en: 27 Wis. Int'l L.J, p. 607.

BARTON, Philip (2001): "State Responsibility and Climate Change: Could Canada be Liable to Small Island States?", en: 11 Dalhousie Journal of Legal Studies, p. 83.

Duong, Tiffany T.V. (2009-2010): "When Islands Drown: The Plight of "Climate Change Refugees" and Recourse to International Human Rights Law", en: 31 U.Pa. J, Int'l L., p. 1234.

DAvis, Joy-Dee. (2005): "State Responsibility for Climate Change: The Case of the Maldives", en: Master of Arts in Law and Diplomacy Thesis, The Fletcher School, p. 49.

DiAz, Leticia, Dubner, Barry et al. (2007), "When is a 'rock' an 'island'?-Another unilateral declaration defies "norms' of international law, en: 15 Michigan State Journal of International Law, p. 533.

Dubner, Barry (1995), "The Spratly "Rocks" Dispute-A "Rockapelago" Defies Norms of International Law", en: 9 Temp. Int' L \& Comp. L.J., p. 300.

KNOX, John (2009): "Linking Human Rights and Climate Change at the United Nations", en: 33 Harv. Envtl. L. Rev., p. 480.

MCleman, Robert (2009-2010): "Climate Change Migration, Refugee Protection, and Adaptive Capacity-Building", en: 4 McGill Int'l J. Sust. Dev. L. \&Pol'y 12008.

StANImIR A. Alexandrov (2006), "The Compulsory Jurisdiction of the International Court of Justice: How Compulsory is it?", en: Chinese Journal of International Law (Vol. 5, № 1), 29-38.

Stallard, Hannah (2009): "Turning up the Heat on Tuvalu: An Assessment of Potential Compensation for Climate Change Damage in Accordance with States Responsibility under International Law", en: 15 Canterbury L. Rev., pp. 165-176.

TOL, Richard y VERHEYEN, Roda (2004): "State responsibility and compensation for climate change damage: a legal and economic assessment", en: 32 Energy Policy, p. 1112.

\section{Otros documentos ACADÉMICOS}

Declaration of the United Nations on the Human Environment (Stockholm), U.N. Doc. A/Conf.48/14/Rev. 1 (1973). 
ILC, Draft Articles on Prevention of Transboundary Harm from Hazardous Activities, with commentaries, UN GAOR, 56th Sess., Supp. № 10, UN Doc. A/56/10 (2001) 377.

ILC Draft Articles on State Responsibility of States for the Internationally Wrongful Acts with Commentaries, Yearbook of the International Law Commission, 2001, Vol. II, Part Two, pp. 34 y ss.

ILC, Fragmentation of International Law: Difficulties Arising from the Diversification and Expansion of International Law, Report of the Study Group of the International Law Commission, Finalized by Martti Koskenniemi, A/ CN.4/L.882, 13 April 2006, p. 240, para. 475.

ILC, Report of the International Law Commission Covering the Work of its Eight Session, U.N. GAOR $11^{\text {th }}$ Sess., Supp. № 9, pp. 16-17, U.N. Doc. A/3159 (1956).

IPCC, Regional Impacts of Climate Change: An Assessment of Vulnerability (1998).

PARK, Susin. Head, UNHCR Office for Switzerland and Liechtenstein. Climate Change and the risk of statelessness: The Situation of low-lying Island States. Legal and protection policy research series. Division of International Protection United Nations High Commissioner for Refugees (UNHCR), may 2011.

Rio Declaration on Environment and Development (Rio de Janeiro), UN Doc. A/CONF.151/26 (Vol. I).

Imperial Conference, Report of Inter-Departmental Committee on the Limits of Territorial Waters, Document T.118/118/380 (1924), p. 5.

\section{Documentos ELECTRÓNICOS}

Gagain, Michael (2012): "Climate Change, Sea Level Rise, and Artificial Islands: Saving the Maldives's Statehood and Maritime Claims through the Constitution of the Oceans", p. 99. Disponible en: http://www.colorado. edu/law/sites/default/files/GAGAIN\%20_correctedv2_.pdf [visitado el 18/12/2014].

LanG, Olivia (2009): "Maldives Leader in Climate Change Stunt", en: BBC News, Oct. 17/2009. Disponible en: http://news.bbc.co.uk/2/hi/8312320. stm[visitado el 21/12/2014].

United Nations (1989): "Office for Ocean Affairs and the Law of the Sea, Baselines: An Examination of the Relevant Provisions of the United Nations Convention on the Law of the Sea". Disponible en: http://www.un.org/depts/ los/doalos_publications/publicationstexts/The\%20Law\%20of\%20the $\% 20$ Sea_Baselines.pdf [visitado el 19/11/2014]. 
Villalta, Ana Elizabeth (2006): "La Contribución de América al Derecho Internacional", p. 65. Disponible en: http://www.oas.org/dil/esp/59-94\%20 Villalta\%20def.pdf [visitado el 10/08/2014].

\section{NORMAS JURÍDICAS CITADAS}

Convención de Naciones Unidas sobre el Derecho del Mar, 1833 UNTS 3.

Convenio de Ginebra sobre Mar Territorial y Zona Contigua, 516 UNTS 205.

Convención Marco de las Naciones Unidas sobre Cambio Climático, 1771 UNTS 107.

Convención de Montevideo sobre Derechos y Deberes de los Estados. Montevideo, 1933, 165 LNTS 19.

Convención Internacional sobre la Eliminación de Todas las Formas de Discriminación Racial, 21 de diciembre de 1965, 660 UNTS 195.

Estatuto de la Corte Internacional de Justicia, 33UNTS 993.

\section{JURISPRUDENCIA CITADA}

Bosnia Herzegovina v. Yugoslavia (1996): Application of the Convention on the Prevention and Punishment of the Crime of Genocide, Preliminary Objections, Judgment, en: 1. C. J. Reports, p. 613, para. 25 in fine.

Argentina v. Uruguay (2010): Pulp Mills on the River Uruguay, Judgment, en: I.C.J. Reports, p. 14 para.193.

Bangladesh and India (2014): Award in the matter of the Bay of Bengal Maritime Boundary Arbitration between The People's Republic of Bangladesh and the Republic of India, en: The Hague, 7 July.

Benin/Niger (2005): Frontier Dispute Judgment, en:I.C.J. Reports, p. 90.

Bosnia-Herzegovina v Yugoslavia (2003): Application for Revision of the Judgment of 11 July 1996 in the Case concerning Application of the Convention on the Prevention and Punishment of the Crime of Genocide (Bosnia-Herzegovina v Yugoslavia), Preliminary Objections (Yugoslavia v Bosnia and Herzegovina), Judgment, en: I.C.J. Reports.

Cameroon v. United Kingdom (1963): Case concerning the Northern Cameroons, Preliminary Objections, Judgment of 2 December 1963, en: I.C. J. Reports, p. 15, p. 29.

Portugal v. India (1957): Case concerning right of passage over Indian territory (Preliminary Objections), Judgment of November 26th, 1957, en: I.C.J. Reports, p. 125.

Case concerning the delimitation of maritime boundary between Guinea-Bissau and Senegal, 31 July 1989.

Italy v. France (1954): United Kingdom of Great Britain and Northern Ireland and United States of America Case of the monetary gold removed from 
Rome in 1943 (Preliminary Questions), Judgment of June 15th, 1954, en: I.C.J. Reports, p. 19.

United Kingdom of Great Britain and Northern Ireland v. Albania (1949): Corfu Channel case Judgment of December 15th, 1949, en: I.C.J. Reports, p. 244. United States/Canada (1984): Delimitation of the Maritime Boundary in the Gulf of Maine Area, Judgment, en: I.C.J. Reports.

Democratic Republic of the Congo v. Rwanda (2006): Armed Activities on the Territory of the Congo (New Application: 2002), Jurisdiction and Admissibility, Judgment, en: I.C.J. Reports, p. 6.

Democratic Republic of the Congo v. Rwanda (2006): Jurisdiction and Admissibility, Judgment, en: I.C.J. Reports, p. 40, para. 90.

Djibouti v. France (2008): Certain Questions of Mutual Assistance in Criminal Matters, Judgment, en: I.C.J. Reports, p. 177.

Ethiopia v. South Africa; Liberia v. South Africa (1962): South West Africa Preliminary Objections, Judgment, en: I.C.J. Reports, p. 328.

(Francev. Norway), Certain Norwegian Loans Judgment, I.C.J. Reports 1957, p. 25 Free Zones of Upper Savoy and the District of Gex, Judgment of 7 June 1932, P.C.I. J., Series A/B, No 46, p. 161.

Georgia v. Russian Federation (2011):; Application of the International Convention on the Elimination of All Forms of Racial Discrimination (Georgia v. Russian Federation), Preliminary Objections, Judgment, en: I.C.J. Reports, p. 70.

Germamy v. Italy: Greece Intervening (2012): Jurisdictional Immunities of the State, Judgment, en: I.C.J. Reports, p. 99.

Colombia v. Perú (1951): Haya de la Torre case, en: I.C. J. Reports, pp. 78-79. Interpretation of Peace Treaties with Bulgaria, Hungary and Romania, First Phase (1950): Advisory Opinion, en: I.C.J. Reports, p. 74.

Islamic Republic of Iran v. United States of America (2003): Oil Platforms (Islamic Republic of Iran v. United States of America), Judgment, en: I.C.J. Reports, p. 161.

Legality of the Threat or Use of Nuclear Weapons (1996): Advisory Opinion, en: I.C.J. Reports, p. 226, para. 29.

Libyan Arab Jamahiriya/Chad "Territorial Dispute (1994): Judgment, en: I.C.J. Reports, p. 6.

Libyan Arab Jamahiriya v. United Kingdom (1998): Questions of Interpretation and Application of the 1971 Montreal Convention arising from the Aerial Incident at Lockerbie), Preliminary Objections, Judgment, en: I. C.J. Reports, p. 23, para. 36.

Marshall Islands v. Pakistan: Case concerning Negotiations relating to Cessation of the Nuclear Arms Race and to Nuclear Disarmament, Application Instituting Proceedings against Pakistan/United Kingdom/India, submitted on 24 April 2014. 
Nauru v. Australia (1992): Certain Phosphate Lands in Nauru, Preliminary Objections, Judgment, en: I.C.J. Reports, p. 240.

The Netherlands/United States of America: Island of Palmas case Award of 4 April 1928, en: UNRIAA (Vol. II), pp. 845 y 839.

Nicaragua v. Colombia (2012): Territorial and Maritime Dispute, Judgment, en: I.C.J. Reports, p. 624, p. 673, para. 138.

Nicaragua v. Costa Rica (2013): Construction of a Road in Costa Rica Along the San Juan River, Order, en: I.C.J, 13 December, para. 9.

Nicaragua v. Honduras (2007): Territorial and Maritime Dispute between Nicaragua and Honduras in the Caribbean Sea Judgments, en: I.C.J. Reports, p. 659.

North Sea Continental Shelf (1969): Judgment, en: I.C.J. Reports.

Opinion No 1 of the Arbitration Commission of the Peace Conference on Yugoslavia (1992):31 ILM 1494, pp. 1492-1497 (opinion no. 1).

Pakistan v. India (2000): Aerial Incident of 10 August 1999 Jurisdiction, Judgment, en:I.C.J. Reports, p. 24, para. 26.

Peru v. Chile (2008): Case concerning the Maritime Dispute Application instituting proceedings, 16 January. Disponible en: http://www.icj-cij.org/docket/ files/137/14385.pdf. [visitado el 28/06/2014].

Republic of Guinea v. Democratic Republic of the Congo (2012): Ahmadou Sadio Diallo Compensation, Judgment, en: I.C.J. Reports, p. 324.

Romania/Ukraine (2009): Maritime Delimitation in the Black Sea, en: I.C.J Reports, p. 105, para. 127.

Serbia and Montenegro v. Belgium (2004): Legality of Use of Force Preliminary Objections, Judgment, en: I.C.J. Reports, p. 279.

The Former Yugoslav Republic of Macedonia v. Greece (2011): Application of the Interim Accord of 13 September 1995, Judgment of 5 December 2011, en: I.C.J. Reports, p. 644.

United States Diplomatic and Consular Staff in Tehran, Judgment, en: 1. C. J. Reports, p. 20, para. 37. 